\title{
EL ÁMBITO DE APLICACIÓN DE LAS LIBERTADES \\ EUROPEAS QUE AFECTAN AL DERECHO DE FAMILIA \\ Y LAS RELACIONES ENTRE EL ORDEN PÚBLICO DE LA UE Y EL DE LOS ESTADOS MIEMBROS
}

\author{
THE SCOPE OF APPLICATION OF THE EUROPEAN FREEDOMS \\ RELATED WITH FAMILY LAW AND THE RELATIONS \\ BETWEEN PUBLIC ORDER OF THE EUROPEAN UNION AND \\ THAT OF THE MEMBER STATES
}

\author{
NATIVIDAD GoÑI URRIZA \\ Profesora Titular de Derecho Internacional Privado \\ Universidad Pública de Navarra \\ ORCID ID:0000-0003-0119-3249
}

Recibido: 10.07.2021 / Aceptado: 27.07.2021

DOI: https://doi.org/10.20318/cdt.2021.6257

\begin{abstract}
Resumen: De la jurisprudencia dictada por el Tribunal de Justicia en aplicación de las libertades europeas en casos transnacionales que afectan al Derecho de Familia se extraen una serie de derechos fundamentales que, teniendo su reflejo en la Carta de Derechos Fundamentales de la Unión, configurarían lo que ha venido a denominarse el orden público de la Unión Europea. Los Estados miembros también disponen de su propio orden público que formando parte de la identidad nacional (art. 4.2 TUE) constituiría un límite a las libertades europeas. De la Jurisprudencia del Tribunal de Justicia se deduce un método para establecer su ámbito de aplicación y las relaciones entre uno y otro.

Palabras clave: orden público, libertades de circulación y de residencia, Carta de Derechos Fundamentales, derechos Fundamentales de la Unión.
\end{abstract}

Abstract: From the jurisprudence issued by the Court of Justice in application of the European freedoms in cross border cases that affect Family Law, a series of fundamental rights are extrapolated that, having their reflection in the Charter of Fundamental Rights of the Union, would configure what has come to be called the public order of the European Union. Member States also have their own public order which, forming part of the national identity (art. 4.2 TEU), would constitute a limit to European freedoms. From the jurisprudence of the Court of Justice a method is deduced to establish the scope of application and the relations between one and the other.

Keywords: public order, movement and residence freedoms, Fundamental Rights Charter, European Union Fundamental Rights.

Sumario: I. Introducción. II. Ámbito de aplicación del "orden público europeo". 1) La conexión del supuesto con las libertades europeas y el derecho derivado. 2) Contenido y distinción de ambas libertades. A) Derecho de residencia. B) Derecho de circulación. 3) Beneficiarios. A) Nacionales de los Estados miembros. B) Nacionales de terceros Estados. C) Situaciones reguladas por la Directiva 2004/38. 4) Situaciones puramente internas. A) La doble nacionalidad. B) Ejercicio de las libertades europeas sin traslado. III. Límites a las libertades europeas que afectan al orden 
público en Derecho de familia. 1) Coexistencia de principios fundamentales de los ordenamientos jurídicos europeo y nacional. 2) Test de legitimidad del objetivo perseguible por el Estado miembro. 3) Del objetivo legítimo a la identidad nacional. 4) Necesidad y adecuación. 5) Proporcionalidad y objetividad de la medida. IV. El orden público como límite a las libertades del mercado interior en la Directiva 2004/38.

\section{Introducción}

1. El establecimiento de derechos fundamentales a nivel europeo a través de la adopción de la Carta de Derechos Fundamentales de la UE en 2010 no deroga los principios propios de los Estados miembros que configuran la identidad nacional ${ }^{1}$. De modo que cada Estado miembro mantiene su propio orden público internacional, orden público que puede variar en el espacio y en el tiempo y cuya realidad es reconocida en el Derecho de la Unión².

Sin embargo, el Derecho de la UE, y por lo que nos interesa aquí, las libertades europeas que afectan al Derecho de Familia, se han configurado como un límite no sólo a la aplicación del derecho de los Estados miembros sino incluso a su orden público en los casos transnacionales ${ }^{3}$.

Las libertades europeas objeto de estudio en este trabajo constituyen el mercado interior, considerado como un espacio sin fronteras interiores en el que la libertad de circulación está garantizada con arreglo a las disposiciones del Tratado (considerando 2 Directiva 2004/38).

2. La solución del Tribunal de Justicia en el caso Coman cuando indica que el Derecho de la Unión obliga a un Estado miembro a considerar cónyuge a una persona que ha contraído matrimonio legal en otro Estado miembro recuerda al principio del mutuo reconocimiento de situaciones jurídicas ${ }^{5}$. El Tribunal de Justicia ha aplicado este principio en relación a situaciones relativas a la persona y a la familia creadas en un Estado miembro cuando está en juego el ejercicio de una libertad europea.

3. Este principio de mutuo reconocimiento que se estableció por el TJUE años antes para garantizar las libertades económicas que configuran el Mercado Interior supuso una relación compleja de una materia cuya competencia es compartida por la Unión y los Estados miembros (art. 4.2, letra a TUE).

El principio del reconocimiento mutuo se aplicó por primera vez en el año 74 en la interpretación del actual artículo 34 TFUE relativo a la libre circulación de mercancías en el famoso caso Cassis de Dijon ${ }^{6}$. En dicha sentencia el Tribunal consideró que debía reconocerse que la mercancía producida conforme a la legislación de un Estado miembro debía poder ser comercializada en otro Estado miembro. Esto tuvo como consecuencia la aplicación del principio de reconocimiento mutuo, no sólo de las legislaciones de fabricación de los productos sino el reconocimiento de las certificaciones?

\footnotetext{
${ }^{1} \mathrm{https} / /$ www.europarl.europa.eu/charter/pdf/text_es.pdf

${ }^{2}$ Sobre la noción de orden público en Derecho Internacional Privado, véase A.L. CAlvo Caravaca/J. CARRAScosa GonzÁlez y отros, Tratado de Derecho Internacional Privado, Vol. 1, Valencia, Tirant Lo Blanc, 2020, pp. 754-797.

${ }^{3}$ STJUE de 5 junio 2018, C-672/16, Coman, EU:C:2018:134.

${ }^{4}$ Directiva 2004/38/CE del Parlamento Europeo y del Consejo de 29 de abril de 2004relativa al derecho de los ciudadanos de la Unión y de los miembros de sus familias a circular y residir libremente en el territorio de los Estados miembros, por la que se modifica el Reglamento (CEE) no1612/68 y se derogan las Directivas 64/221/CEE, 68/360/CEE, 72/194/CEE, 73/148/CEE, 75/34/CEE, 75/35/CEE, 90/364/CEE, 90/365/CEE y 93/96/CEE, https://eur-lex.europa.eu/legal-content/ES/ TXT/PDF/?uri=CELEX:02004L0038-20110616\&from=ES

${ }^{5}$ STJUE de 5 junio 2018, C-672/16, Coman, apdo. 51, EU:C:2018:134. Para un análisis de las implicaciones de esta sentencia, véase M. GRASSI, "Sul riconoscimento dei matrimoni contratti all'estero tra persone dello stesso sesso: il caso Comen" RDIPP, 2017, pp. 739-776, concr. p. 755.

${ }^{6}$ STJCE de 20 de febrero 1979, Cassis de Dijon, asunto 120/78, apdo. 8, EU:C:1979:42.

${ }^{7}$ STJ 14 julio 1988, Samnor, asunto 298/87, 1988, EU:C:1988:415; STJ de 14 julio 1988, Drei Glocken v. USL CentroSud, 1988, asunto 407/85, EU:C:1988:401 y STJ de 6 octubre 2011, Philippe Bonnarde v. Agence de Services etde Paiment, C-443/10, EU:C:2011:641. P. Craig \& G. DE BúrCA, EU Law. Text, cases and Materials, Oxford, University Press, 2020.
} 
4. Las libertades europeas que configuran el mercado interior económico están en vigor desde el año 1958, sin embargo, la libertad de residencia y de circulación de personas que no realizaban actividades económicas son derechos incluidos en el ordenamiento jurídico europeo por el Tratado de Maastricht derivados de la ciudadanía de la Unión (arts. 18-25 TFUE).

5. La relación entre el que podríamos llamar "orden público europeo" y el "orden público estatal" se ha planteado en materia de persona y familia con motivo de la aplicación de la libertad de circulación y de residencia previstos en los artículos 20 y 21 TFUE.

6. En el propio Tratado de Funcionamiento se prevé que los Estados miembros pueden oponer a la aplicación de las cuatro libertades que constituyen el mercado interior intereses estatales contemplados en el Tratado ${ }^{8}$. De la aplicación de las libertades que constituyen el mercado interior y de los límites previstos, tanto en el Tratado de Funcionamiento como jurisprudencialmente-motivos de interés general- se deduce un procedimiento, de interpretación y de aplicación de las libertades y de los límites que se se aplica igualmente para la aplicación de las libertades fundamentales de circulación y residencia previstas en los artículos 20 y 21 TFUE.

7. La jurisprudencia dictada en interpretación de los derechos de residencia y de circulación de los ciudadanos de la Unión y del derecho derivado, por un lado, y de los límites a dichas libertades, por otro, muestra el procedimiento para delimitar el ámbito de aplicación de estos derechos fundamentales de la Unión y el ámbito reservado al "orden público de los Estados miembros" .

8. En este trabajo se describirá el método que utiliza el Tribunal de Justicia para la aplicación de los derechos fundamentales derivados de la ciudadanía de la Unión y los límites estatales admitidos por el Derecho de la Unión en Derecho de la Persona y de la Familia ${ }^{10}$. En primer lugar, se delimitará las situaciones transnacionales que determinan la aplicación de los derechos de circulación y residencia del Tratado de Funcionamiento, es decir, la situación jurídica debe implicar la aplicación de una libertad europea (II). En segundo lugar, se plantearán los términos en los que un Estado miembro puede adoptar medidas restrictivas que, justificadas por razones de interés general, o por razones de orden público, seguridad pública o salud pública, pueden limitar la aplicación de los derechos fundamentales de la Unión. En este apartado se tratará la evolución reciente desde el concepto de objetivo legítimo a la identidad nacional - el artículo. 4.2 TUE- (fundamentalmente en el caso Coman y en el caso V.M.A). En la aplicación de estas reglas tiene cabida y se presenta la colisión entre el "orden público de la UE" y el "orden público de los Estados miembros" dado que la restricción a la libertad europea sólo puede justificarse para perseguir un objetivo legítimo desde el punto de vista del orden público de la UE.

\section{II. Ámbito de aplicación del "orden público europeo"}

\section{1) La conexión del supuesto con las libertades europeas y el derecho derivado}

9. La manifestación de los principios fundamentales que configurarían el llamado "orden público europeo" se produce en situaciones comprendidas dentro del ámbito de aplicación ratione materiae del Derecho de la Unión, es decir debe tratarse de situaciones en las que se vea implicado el ejercicio de

\footnotetext{
${ }^{8}$ N. Stoffel Valloton, La prohibición de restricciones a la libre circulación de mercancías en la Comunidad Europea, Dykinson, Madrid, 2000, p. 72.

${ }^{9}$ Para una vision complete y actualizada de las libertades del Mercado interior véase, CraIG \& G. DE BúrCA, EU Law. Text, cases and Materials, Oxford, University Press, 2020.

${ }^{10}$ La cuestión del orden público europeo en relación a otros derechos fundamentales afecta también a otras situaciones privadas internacionales que ya han sido objeto de estudio. Véase, R. GonzÁlez González, "Límites a la construcción de un orden público europeo en materia de derechos fundamentales (A propósito de la sentencia TJCE Krombach c. Bamberski, de 28 de marzo de 2000)", Revista de Derecho Comunitario Europeo, núm. 8, 2000, pp. 593-617.
} 
las libertades del mercado interior garantizadas por el TFUE, en particular las relativas al ejercicio de las libertades de circulación y de residencia en el territorio de los Estados miembros tal y como se haya reconocida en los artículos 20.2 , letra a) y $21 \mathrm{TFUE}^{11}$.

Estas normas del Tratado en materia de libre circulación de personas y los actos adoptados para la ejecución de éstas -la Directiva 2004/38, fundamentalmente- no pueden aplicarse a situaciones que no presenten ningún punto de conexión con alguna de las situaciones contempladas por el Derecho de la Unión y cuyos elementos pertinentes estén todos situados en el interior de un solo Estado miembro ${ }^{12}$. De modo que, en estos últimos casos, el Derecho europeo no rige la situación y tampoco son aplicables los derechos reconocidos por la Carta de Derechos Fundamentales (art. 51.1 CEDF).

10. El Tribunal de Justicia ha afirmado que la ciudadanía de la Unión se convierte en el estatuto fundamental de los nacionales de los Estados miembros que permite a quienes se encuentran en la misma situación obtener, en el ámbito de aplicación ratione materiae del Tratado de Funcionamiento, independientemente de su nacionalidad y sin perjuicio de las excepciones expresamente previstas a este respecto, el mismo trato jurídico. Dentro de las situaciones comprendidas en el ámbito de aplicación del Derecho de la Unión están las relativas al ejercicio de las libertades fundamentes, en particular las relativas a la libertad de circulación y de residencia en el territorio de los Estados miembros ${ }^{13}$.

Esta libre circulación de personas ha sido reafirmada por el art. 45 de la Carta de los Derechos Fundamentales de la Unión Europea (CEDF) $)^{14}$. Esta norma indica que:

1. Todo ciudadano de la Unión tiene derecho a circular y residir libremente en el territorio de los Estados miembros.

2. De conformidad con lo dispuesto en el Tratado constitutivo de la Comunidad Europea, se podrá conceder libertad de circulación y de residencia a los nacionales de terceros países que residan legalmente en el territorio de un Estado miembro.

11. Esta vinculación de las situaciones privadas con el Derecho de la Unión se refleja muy bien en el caso Coman, en el que se discute el concepto de cónyuge en el Derecho de Rumanía ante la denegación del permiso de residencia al Sr. Hamilton, nacional estadounidense con el que el Sr. Coman contrajo matrimonio homosexual en Bélgica -durante un periodo de residencia en ese país-. Si el Sr. Coman -nacional rumano- no hubiera contraído matrimonio con un nacional de un tercer Estado, mientras residía en otro Estado de la Unión, sino en un tercer Estado, los USA por ejemplo, al no haber ejercido el señor Coman la libertad de circulación derivada del art. 21 TFUE -constituyó una relación familiar allí-, el orden público rumano no se hubiera visto "limitado" por la normativa europea y por el "orden público de la UE". Los principios fundamentales de la Unión Europea no se hubieran aplicado al caso y Rumanía no habría visto limitado su concepto de familia y de cónyuge por aplicación de la Directiva 2004/38. Rumanía hubiera aplicado su Derecho de extranjería ya que la situación no afectaría a las libertades de circulación y de residencia de un ciudadano de la Unión. Por tanto, la aplicación de estas libertades europeas que afectan al Derecho de Familia constituye el fundamento y los límites de la aplicación de los principios fundamentales del Derecho de la Unión. Es por ello una premisa determinar el régimen y el ámbito de aplicación de los derechos de residencia y circulación del TFUE.

12. Estas libertades de residencia y de circulación de los ciudadanos de la Unión y de sus familiares confieren a todo ciudadano de la Unión un derecho primario e individual a circular y a residir libremente en el territorio de los Estados miembros. La Directiva 2004/38 sobre el derecho de los ciuda-

\footnotetext{
${ }^{11}$ STJUE de 15 noviembre 2011, C-256/11, Dereci, apdos. 70-74, EU:2011:734.

${ }^{12}$ STJUE de 15 noviembre 2011, C-256/11, Dereci, apdo. 60, EU:2011:734 y STJUE de 5 mayo 2011, C-434/09, McCarthy, apdo.48, EU:C:2011:277.

${ }^{13}$ STJUE de 2 octubre 2003, García-Avelló, C-148/02, apdos. 23 y 24 . EU:C:2003:539 y STJUE de 5 mayo 2011, C-434/09, McCarthy, apdo.27, EU:C:2011:277.

${ }^{14}$ STJUE de 7 octubre 2010, C-162/09, Lassal, apdo. 29. EU:C:2010:592.
} 
danos de la Unión y de sus familiares a circular y residir en la UE trata de facilitar el ejercicio de ambas libertades ${ }^{15}$.

13. El texto literal del artículo 21 del TFUE (antiguo artículo 18 TCE) indica que: "1. Todo ciudadano de la Unión tendrá derecho a circular y residir libremente en el territorio de los Estados miembros, con sujeción a las limitaciones y condiciones previstas en los Tratados y en las disposiciones adoptadas para su aplicación."

Por su parte, el art. 20.2, letra a TFUE indica que: "2. Los ciudadanos de la Unión son titulares de los derechos y están sujetos a los deberes establecidos en los Tratados. Tienen, entre otras cosas, el derecho: a) de circular y residir libremente en el territorio de los Estados miembros; ".

Estas libertades constituyen un derecho directo, autónomo y efectivo de residir en territorio de la Unión Europea y de circular de un Estado miembro a otro ${ }^{16}$. Existe jurisprudencia reiterada afirmando el efecto directo de estas normas ${ }^{17}$.

La aplicación de estas libertades a todos los ciudadanos de la Unión, con indiferencia de su situación laboral tiene consecuencias muy relevantes sobre el régimen de los Estados miembros en materia de Derecho de extranjería ${ }^{18}$, sobre las normas de derecho al nombre y los apellidos de las personas físicas ${ }^{19}$, sobre el régimen de los permisos de trabajo y prestaciones sociales ${ }^{20} \mathrm{y}$, sobre los principios fundamentales del Derecho de Familia o el orden público de los Estados miembros ${ }^{21}$.

14. El artículo 20.2 TFUE, en su segundo párrafo indica que los derechos de residencia y de circulación se ejercerán en las condiciones previstas en las normas de desarrollo de los mencionados preceptos del Tratado. La norma fundamental de desarrollo es la referida Directiva 2004/38 que ha sido traspuesta a nuestro ordenamiento jurídico a través del Real Decreto 240/200722.

Esta normativa consolida la legislación previa relativa a la libertad de movimientos de las personas en un único texto normativo ${ }^{23}$. Asimismo, crea un régimen legal único de la libertad de residencia y

${ }^{15}$ Considerando cuarto de la Directiva 2004/38/CE del Parlamento Europeo y del Consejo de 29 de abril de 2004relativa al derecho de los ciudadanos de la Unión y de los miembros de sus familias a circular y residir libremente en el territorio de los Estados miembros, por la que se modifica el Reglamento (CEE) no1612/68 y se derogan las Directivas 64/221/CEE, 68/360/ CEE, 72/194/CEE, 73/148/CEE, 75/34/CEE, 75/35/CEE, 90/364/CEE, 90/365/CEE y 93/96/CEE, https://eur-lex.europa.eu/ legal-content/ES/TXT/PDF/?uri=CELEX:02004L0038-20110616\&from=ES

${ }^{16}$ P. Craig \& G. DE BúrCa, EU Law. Text, cases and Materials, Oxford, University Press, 2020, p. 896.

${ }^{17}$ STJCE 17 septiembre 2002, C-413/99, Baumbast, 2002, EU:C:2001:385.

y fue confirmada por la STJUE 19 octubre 2004, C-200/02, Zhu and Chen v. Secretary of State of the Home Department, EU:C:2004:639.

${ }^{18}$ STJUE de 5 mayo 2011, C-434/09, McCarthy, apdo. EU:C:2011:277; STJUE de 15 noviembre 2011, C-256/11, Dereci, EU:2011:734 y STJUE de 13 julio 2017, C-193/16, E y Subdelegación del Gobierno de Álava, EU:C2017:542.

${ }^{19}$ STJUE 2 octubre 2003, C-148/02, García-Avelló, EU:C:2003:539.

STJUE de 22 diciembre 2010, C-208/09, Sayn-Wittgenstein, EU:C:2010:806, STJUE de 12 mayo 2011, Runevic-Vardyn y Wardyn, C-391/09, EU:C:2011:291, STJUE de 2 junio 2016, C-438/14, Bogendorff, EU:C:2016:401

${ }^{20}$ STJUE de 8 marzo 2011, C-34/09, Ruiz Zambrano, EU:C:2011:124. M. Del Rosario Carmona LuQue, "TJUE - sentencia de 08.03.2011 (gran sala), Ruiz zambrano/office national de l'emploi, «ciudadanía de la unión - artículo 20 tfue - derecho de residencia de un menor en el estado miembro del que es nacional con independencia del ejercicio de la libre circulación - concesión de un derecho de residencia derivado al ascendiente no comunitario que asume la manutención del menor» el disfrute efectivo de la esencia de los derechos de ciudadanía de la unión, Revista de derecho Comunitario Europeo, núm. 38, 2011, pp. 185-202; K. Lenaerts/J A. Gutiérrez Fons, "Ruiz Zambrano (C-34/09) o de la emancipación de la Ciudadanía de la Unión de los límites inherentes a la libre circulación", REDE, 40, 2011, pp. 493-532; P. ABARCA JunCO/M. VARGAS GómEZ-UrRUTIA, "Estatuto de ciudadano de la Unión y su posible incidencia en el ámbito de aplicación del Derecho Comunitario (STJUE Ruiz Zambrano)" REEI, núm. 23, 2012 y M. Vargas Gómez-URrutia, "Cuando los apellidos traspasan la frontera. Reflejos de la desigualdad en el nombre de la persona en el asunto "Losonci-Rose c. Suiza" y en la jurisprudencia del TJUE", RGDE. Iustel., núm. 28, 2012, pp. 1-28.

${ }^{21}$ STJUE de 22 diciembre 2010, C-208/09, Sayn-Wittgenstein, EU:C:2010:806; STJUE de 12 mayo 2011, Runevic-Vardyn y Wardyn, C-391/09, EU:C:2011:291 y STJUE de 2 junio 2016, C-438/14, Bogendorff, EU:C:2016:401; STJUE de 5 junio 2018, C-672/16, Coman, EU:C:2018:134 y Conclusiones AG J. Kokott de 15 abril 2021, C-490/20, V.M.A., EU:C:2021:296.

${ }^{22}$ Real Decreto 240/2007, de 16 de febrero, sobre entrada, libre circulación y residencia en España de ciudadanos de los Estados miembros de la Unión Europea y de otros Estados parte en el Acuerdo sobre el Espacio Económico Europeo, BOE núm. 51, de 28 febrero 2007.

${ }^{23}$ Las libertades de entrada y residencia de nacionales de terceros Estados puede estar regulada también por la Directiva 
de circulación de todos los ciudadanos de la UE que se aplica con independencia de la situación laboral o sean estudiantes, incluso si las personas ejercen el derecho de establecimiento o la libre prestación de servicios $^{24}$. Por tanto, constituye el estatuto fundamental o básico de las libertades de los nacionales de los Estados miembros.

\section{2) Contenido y distinción de ambas libertades}

15. En principio, las libertades mencionadas se aplican a las situaciones vinculadas con el Derecho de la Unión porque implican a nacionales de un Estado miembro que residen legalmente en el territorio de otro Estado miembro ${ }^{25}$. Con carácter general, dadas las dos circunstancias mencionadas -la nacionalidad de un Estado miembro y la residencia legal en otro distinto- son de aplicación los artículos 20 y 21 TFUE.

Sin embargo, el Tribunal de Justicia también ha indicado que las libertades de circulación y residencia no siempre se ejercen de manera conjunta, así, en los casos García-Avelló y Ruiz Zambrano, ha interpretado el artículo 20 TFUE en el sentido de que el Derecho de residencia se aplica a un menor en el territorio del Estado miembro del que es nacional con independencia de que éste haya ejercido previamente su derecho a la libre circulación ${ }^{26}$. Esta interpretación fue confirmada en el caso Zhu Chen en el que se establece que no es necesario haberse desplazado de un Estado miembro a otro para que un nacional de un Estado miembro pueda beneficiarse de las libertades de circulación y residencia ${ }^{27}$.

El TJUE ha afirmado, en varias ocasiones, que la situación de un sujeto que ostenta la nacionalidad de un Estado miembro que ha nacido en otro Estado de la Unión (Estado de acogida) y que no ha ejercitado el derecho a la libre circulación no puede considerarse, sólo por esa razón, una situación puramente interna, que impide al citado nacional alegar en el Estado miembro de acogida las disposiciones comunitarias en materia de libre circulación y de residencia de las personas ${ }^{28}$.

16. En una línea jurisprudencial posterior, iniciada con el caso Chávez-Vílchez, el Tribunal diferencia, de manera más precisa, la aplicación del 21 TFUE y del 20 TFUE al presentarse en el mismo situaciones jurídicas distintas. En el caso se distingue, por un lado, la situación de la hija de la Sra. Chávez-Vílchez, de nacionalidad neerlandesa, que vivió en Alemania con sus progenitores antes de volver a los Países Bajos y allí solicitar -la madre venezolana- una prestación familiar de, por otro lado, la situación de los hijos menores de otras demandantes que no ejercieron nunca su derecho a la libre circulación, con anterioridad ni durante el periodo de solicitud de la asistencia social, y residen desde su nacimiento en el Estado miembro cuya nacionalidad poseen. El Tribunal considera que debe aplicarse el artículo 21 TFUE a la hija de la Sra. Chávez-Vílchez y el artículo 20 TFUE a los hijos del resto de demandantes ${ }^{29}$.

En ese mismo asunto el Tribunal establece cual debe ser la relación entre las dos libertades, al aplicar, en primer lugar, el art. 21 TFUE y, si no se cumplen los requisitos de residencia del ciudadano de

2003/86/CE, del Consejo, de 22 de septiembre de 2003, sobre el derecho a la reagrupación familiar (DO L 251). Esta norma fija las condiciones para el ejercicio del derecho de reagrupación familiar de los nacionales de terceros Estados que residen legalmente en la UE. No obstante, esta materia no va a ser objeto de análisis en este trabajo.

${ }^{24}$ La cuestión del orden público de los Estados miembros puede también plantearse en aplicación de la Directiva 2003/86/ CE, del Consejo, de 22 de septiembre de 2003, sobre el derecho a la reagrupación familiar (DO L 251). P. CrAIG \& G. DE BÚRCA, EU Law. Text, cases and Materials, Oxford, University Press, 2020, p. 894 y ss.

${ }^{25}$ STJUE de 2 octubre 2003, C-148/02, García-Avelló, apdo. 27, EU:C:2003:539.

${ }^{26}$ STJUE de 8 marzo 2001, C-34/09, Ruiz Zambrano, EU:C:2011:124.

${ }^{27}$ STJUE de 19 octubre 2004, Zhu and Chen v. Secretary of State of the Home Department, C-200/02, Rec. 2004, p. 9962, apdo. 18. El Tribunal confirma así lo establecido en la sentencia de 2 octubre de 2003, C-148/02, García Avelló, apdos. 13 y 27, EU:C:2003:539.

${ }^{28}$ STJUE de 2 octubre 2003, C-148/02, García-Avelló, apdo 27 EU:C:2003:539; STJUE de 14 octubre 2008, C353/06, Grunkin- Paul, EU:C:2008:559 y STJUE de 19 octubre 2004, C-200/02, Zhu and Chen v. Secretary of State of the Home Department, apdo. 19, EU:C:2004:639.

${ }^{29}$ STJUE de 10 mayo 2017, C-133/15, Chávez-Vilchez, apdo. 49, EU:C:2017:354. 
la Unión en un Estado miembro distinto del de su nacionalidad, deberá examinarse la situación del menor, ciudadano de la Unión, y de su ascendiente, nacional de un tercer país, a la luz del artículo 20 TFUE ${ }^{30}$.

Por tanto, se concluye de esta jurisprudencia que se puede ejercer la libertad de residencia con independencia de la libertad de circulación, cada una de ellas tiene su ámbito de aplicación y su contenido y éstos no coinciden ${ }^{31}$.

\section{A) Derecho de residencia}

17. Por lo que respecta al Derecho de residencia, el artículo 20 TFUE otorga a quien ostenta la nacionalidad de un Estado miembro y, en su caso, a sus familiares de terceros Estados de quien dependan económicamente a residir en el territorio de la Unión ${ }^{32}$. Por ello, el Tribunal en el caso Ruiz Zambrano afirmó que esta disposición se opone a las medidas de los Estados miembro que tengan por efecto privar a los ciudadanos de la Unión de este contenido esencial de estos derechos ${ }^{33}$.

18. El Tribunal de Justicia en Dereci, interpretando el art. 20 TFUE, indicó que el contenido esencial de los derechos conferidos por esta norma se refiere al derecho de residir en la Unión Europea en su conjunto, no en el territorio de un Estado miembro concreto, aunque éste sea el de la nacionalidad que ostenta ${ }^{34}$. Así se desprende claramente de sus afirmaciones: el criterio relativo a la privación del contenido esencial de los derechos conferidos por el estatuto de ciudadano de la Unión guarda relación con situaciones caracterizadas por la circunstancia de que el ciudadano de la Unión se vea obligado de hecho a abandonar no sólo el territorio del Estado miembro del que es nacional, sino también la Unión en su conjunto.

En el caso Chávez-Vílchez el Tribunal confirmó que el derecho de residencia otorga el derecho a no abandonar el territorio de la UE y no de un Estado miembro.

19. Este derecho de residencia no es incondicionado en todos los casos, el art. 20.2 TFUE otorga a una persona nacional de un Estado miembro el derecho a residir por tiempo indefinido en el territorio de otro Estado, el Estado de acogida, siempre que no se convierta en una carga para el erario público de este último -como se verá al analizar la Directiva 2004/38-35.

La esencia de este derecho de residencia se aprecia en toda su virtualidad en el caso Zhu Chen, en que concurren unas circunstancias que llevan al límite el ejercicio de este derecho. Un niño nace en una parte del territorio de un Estado miembro - en Irlanda del Norte que forma parte del Reino Unidoy adquiere, legalmente conforme a las disposiciones de dicho Estado y las irlandesas, la nacionalidad de otro Estado miembro -la irlandesa-, de tal manera que, sin salir del territorio del país de acogida, la situación -nacional de un Estado miembro que solicita el permiso de residencia en otro Estado, del que nunca ha salido y cuya nacionalidad no ostenta- presenta un punto de conexión con las situaciones contempladas en el Derecho de residencia y el artículo 20 es directamente aplicable ${ }^{36}$. No importa que no haya ejercido el Derecho a la libre circulación porque no se había trasladado de un Estado miembro a otro, pero no se trataba de una situación puramente interna dado que el menor ostentaba la nacionali-

${ }^{30}$ STJUE de 10 mayo 2017, C-133/15, Chávez-Vilchez, apdo. 57, EU:C:2017:354.

${ }^{31}$ STJUE de 15 noviembre 2011, C-256/11, Dereci, EU:2011:734

${ }^{32}$ STJUE de 8 marzo 2001, C-34/09, Ruiz Zambrano, apdos. 40-43 y STJUE de 2 marzo 2010, C135/08, Rottmann, apdo. 39, EU:C:2010:104.

${ }^{33}$ STJUE de 8 marzo 2001, C-34/09, Ruiz Zambrano, apdo. 42 y STJUE de 15 noviembre 2011, C-256/11, Dereci, apdo. 64.

${ }^{34}$ STJUE de 15 noviembre 2011, C-256/11, Dereci, apdo. 66, EU:2011:734.

${ }^{35}$ La madre, nacional de un tercer Estado, se traslada a Irlanda del Norte con el fin de que el menor, al nacer, adquiera la nacionalidad irlandesa. Y ello, aunque se reconozca que la adquisición de la nacionalidad se ha obtenido mediante STJUE de 19 octubre 2004, C-200/02, Zhu and Chen v. Secretary of State of the Home Department, EU:C:2004:639.

${ }^{36}$ Destaca como el apartado primero del artículo 20 TFUE tiene efecto directo al otorgar el derecho de residencia a los ciudadanos de la UE que no encajen en ninguna categoría previa existente (trabajadores, estudiantes, o ejercientes de la libre prestación de servicios o del Derecho de establecimiento). P. Craig \& G. DE BúrCA, EU Law. Text, cases and Materials, Oxford, University Press, 2020, p. 899. 
dad de otro Estado, distinto al Estado en el que se solicita la residencia ${ }^{37}$. Si las autoridades británicas deniegan el permiso de residencia a la madre -de nacionalidad china-, el recién nacido, ciudadano de la Unión, tendría que abandonar la Unión y, por tanto, se obstaculizaría su derecho a residir en el territorio de la Unión Europea.

\section{B) Derecho de circulación}

20. Pese a la literalidad del precepto, el artículo 21 TFUE regula un derecho distinto al de residencia. Establece esta disposición el derecho de circulación que implica el derecho a trasladarse desde un Estado miembro hacia otro Estado de la Unión. Por ello son contrarias a esta libertad las medidas de los Estados miembros que disuadan a un ciudadano de la Unión de salir del Estado miembro del que es nacional para ejercer su derecho de residencia en otro Estado miembro, también por la incertidumbre de si podrá volver a su Estado de origen ${ }^{38}$.

Por tanto, esta libertad otorga el derecho a desplazarse y a residir de manera efectiva en un Estado miembro distinto de aquel del que es nacional y de volver al Estado origen.

Se deduce, de todo ello que este derecho se puede invocar frente al Estado miembro de acogida o frente al Estado miembro de origen.

21. Este derecho no debe asimilarse, por el contrario, a las situaciones en las que un sujeto ostenta la doble nacionalidad o resida en un Estado distinto al de su nacionalidad. El mero hecho de que un ciudadano europeo ostente una nacionalidad distinta al Estado donde reside -como se ha señalado en el caso Zhu Chen o tenga doble nacionalidad no implica que esté ejerciendo la libre circulación de personas $^{39}$. El Tribunal en el caso McCarthy entendió que la Sra. McCarthy, doble nacional británica e irlandesa goza del estatuto de ciudadana de la Unión (art. 20 TFUE) y, por ello derecho a alegar, frente a su propio Estado el derecho a circular y residir en el territorio de los Estados miembros (art. 21 TFUE). No obstante, su derecho a residir de manera incondicionada en el Reino Unido deriva del Derecho internacional por poseer dicha nacionalidad y no del Derecho europeo ${ }^{40}$. El hecho de que el Reino Unido no considere su doble nacionalidad a la hora permitir su residencia en Reino Unido no afecta al derecho a circular y residir libremente en el territorio de los Estados miembros. Por tanto, la medida del Reino Unido -que le deniega el permiso de residencia a su marido, nacional jamaicano- no tiene como efecto privarla del disfrute efectivo de las libertades ya que su situación no está regida por el artículo 21 $\mathrm{TFUE}^{41}$. Se trataba, por tanto, de una situación puramente interna.

Por consiguiente, la doble nacionalidad no implica, por sí sola, el ejercicio de la libre circulación de personas. Ni siquiera cuando un sujeto ostenta la nacionalidad de dos Estados miembros puede colegirse que esta circunstancia implique, por sí sola, que se haya ejercido una libertad europea ${ }^{42}$.

\section{3) Beneficiarios}

23. Aunque las disposiciones del Tratado reguladoras de las libertades de circulación y residencia nombran únicamente a los nacionales de los Estados miembros, los derechos que de ellas derivan alcanzan también a sus familiares que no ostenten la nacionalidad de un país europeo, es por ello necesario diferenciar el régimen de unos y otros.

\footnotetext{
${ }^{37}$ STJUE de 19 octubre 2004, C-200/02, Zhu and Chen v. Secretary of State of the Home Department, EU:C:2004:639.

${ }^{38}$ STJUE de 2 octubre 2003, C-148/02, García-Avelló, apdo. 36, EU:C:2003:539 y Sentencia de 14 octubre 2008, C353/06, Grunkin- Paul, apdo. 25, EU:C:2008:559 y STJUE de 5 junio 2018, C-672/16, Coman, apdo. 24, EU:C:2018:134.

${ }^{39}$ STJUE de 19 octubre 2004, C-200/02, Zhu and Chen v. Secretary of State of the Home Department, EU:C:2004:639.

${ }^{40}$ STJUE de 5 mayo 2011, C-434/09, McCarthy, apdos. 29 y 50, EU:C:2011:277.

${ }^{41}$ Ibidem, apdos. 54 y 55.

${ }^{42}$ STJUE de 5 mayo 2011, C-434/09, McCarthy, apdos. 22 y ss, ECLI:EU:C:2011:277.
} 


\section{A) Nacionales de los Estados miembros}

24. Del texto literal de los artículos 20 y 21 TFUE se deduce, sin lugar a dudas, que los derechos de circulación y residencia se otorgan a los nacionales de los Estados miembros de la Unión. Así ha sido interpretado por el Tribunal de Justicia tradicionalmente ${ }^{43}$.

25. El derecho a la libre circulación y de residencia se tiene por las personas por el mero hecho de ostentar la nacionalidad de un Estado miembro, sin que sea necesario cumplir requisitos añadidos, como haber alcanzado una edad mínima para disponer de la capacidad necesaria para ejercitar, por sí mismo, dichos derechos ${ }^{44}$. De este modo, un recién nacido al que se le atribuye la nacionalidad de un Estado miembro, puede solicitar la residencia en otro Estado miembro por tener ese derecho efectivo y directo a la residencia en otro Estado miembro ${ }^{45}$.

26. El Tribunal aplica así a las libertades que afectan al Derecho de Familia el mismo principio que había sido establecido en el año 1992, en un caso de aplicación de las libertades económicas del mercado interior, el caso Micheletti ${ }^{46}$.

En la aplicación de estas libertades, hay que tener en cuenta que la Unión Europea no tiene competencia para otorgar la nacionalidad por lo que, al igual que al determinar las personas físicas beneficiarias de las libertades económicas, esta cuestión queda regulada por el Derecho nacional ${ }^{47}$. Por tanto, la atribución de la nacionalidad, también en el ejercicio de estas libertades que afectan al Derecho de Familia, debe realizarse en aplicación de los principios de Derecho Internacional ${ }^{48}$.

Siguiendo la doctrina del caso Micheletti el resto de Estados de la Unión deben respetar dicha atribución y no puede limitar los efectos de la atribución de la nacionalidad, exigiendo requisitos adicionales para poder ejercer las libertades fundamentales reconocidas en el Tratado ${ }^{49}$. Por tanto, los Estados miembros no pueden añadir requisitos a los ciudadanos de la Unión distintos a la ostentación formal de una nacionalidad de un Estado miembro, no siendo necesario que ésta sea la nacionalidad efectiva ${ }^{50}$.

Esto hace que las normas internas de los Estados sobre la determinación de la solución en los casos de múltiple nacionalidad no sean aplicables a los dobles nacionales en este ámbito. En España no serán de aplicación los artículos $9.9 \mathrm{CC}^{51}$.

27. La naturaleza de principio fundamental de estos Derechos hace que deban interpretarse en sentido amplio ${ }^{52}$. Por ello, los Estados deben respetar la atribución de la nacionalidad por parte del resto de Estados miembros, sin importar el modo en que se ha adquirido, incluso cuando se haya reconocido que se ha modificado el lugar de nacimiento -para adquirir la nacionalidad de un Estado miembro que dispone de normas sobre adquisición de la nacionalidad basadas en el ius soli- con el fin de solicitar, posteriormente, la residencia en otro Estado miembro en aplicación del Derecho de la Unión. Así, el Tribunal de Justicia ha establecido que: Los Estados miembros están facultados para adoptar medidas destinadas a impedir que los particulares, de forma abusiva, obtengan ventajas de las disposiciones

${ }^{43}$ STJUE de 2 octubre 2003, C-148/02, García-Avelló, apdo. 21, EU:C:2003:539; STJUE de 8 marzo 2001, C-34/09, Ruiz Zambrano, apdo. 40-43, EU:C:2011:124 y STJUE de 2 de marzo de 2010, C135/08, Rottmann, apdo. 39, EU:C:2010:104.

${ }^{44}$ STJUE de 19 octubre 2004, C-200/02, Zhu and Chen v. Secretary of State of the Home Department, apdo. 20, EU:C:2004:639 y STJUE 2 octubre 2003, C-148/02, García-Avelló, apdo.21, EU:C:2003:539.

${ }^{45}$ Ibidem.

${ }^{46}$ STJUE de 7 de julio de 1992, C-369/90, Micheletti, apartado 10, EU:C:1992:295.

${ }^{47}$ Sobre los beneficiarios de las libertades de establecimiento y de servicios véase, A L Calvo Caravaca/ J. Carrascosa GonzÁlEZ, Mercado Único y libre competencia en la Unión Europea, Colex, Madrid, 2003, pp. 118-121.

${ }^{48}$ STIJ de 6 abril 1955, Nottebohm, https://www.icj-cij.org/public/files/case-related/18/018-19550406-JUD-01-00-EN.pdf

${ }^{49}$ STJUE de 7 julio 1992, C-369/90, Micheletti, apartado 10, EU:C:1992:295. Posteriormente esta regla fue confirmada en diversas ocasiones, véase, STJUE 2 octubre 2003, C-148/02, García-Avelló, apdo. 28, EU:C:2003:539 y STJUE de 19 octubre 2004, C-200/02, Zhu and Chen v. Secretary of State of the Home Department, apdos.34-40, EU:C:2004:639 34-40.

${ }^{50}$ STJUE de 7 julio 1992, C-369/90, Micheletti, EU:C:1992:295

${ }^{51}$ Ibidem.

${ }^{52}$ STJUE 19 octubre 2004, C-200/02, Zhu and Chen v. Secretary of State of the Home Department, apdo. 40, EU:C:2004:639. 
del Derecho comunitario o que, aprovechando las posibilidades creadas por el Tratado, intenten eludir ilícitamente la aplicación de la legislación nacional ${ }^{53}$.

28. La nacionalidad es requisito sine qua non para ser beneficiario de estas libertades, pero no es condición suficiente cuando la situación está sometida a la Directiva 2004/38, porque se pretende la residencia en otro Estado miembro. En estos casos se requiere que el ciudadano europeo no sea una carga para el Estado de acogida. Esta cuestión se analizará en el epígrafe correspondiente a la Directiva 2004/38.

\section{B) Nacionales de terceros Estados}

\section{a) Naturaleza del derecho}

29. El derecho de los nacionales de terceros Estados a entrar y permanecer en el territorio de la Unión es un derecho derivado, basado en los artículos 20 y 21 TFUE, apartado 1, y en la Directiva $2004 / 38$.

El Tribunal de Justicia ha declarado que dicha Directiva no reconoce derechos de entrada y de residencia en un Estado miembro a todos los nacionales de terceros países, sino únicamente a aquellos que son miembros de la familia, en el sentido del artículo 2, punto 2, de la referida Directiva, de un ciudadano de la Unión que haya ejercido su derecho de libre circulación estableciéndose en un Estado miembro distinto del de su nacionalidad ${ }^{54}$.

En otras palabras, el Tribunal de Justicia, en el asunto Redón Marín, ha afirmado, que los eventuales derechos conferidos a los nacionales de terceros Estados por las disposiciones del Derecho de la Unión relativas a la ciudadanía de la Unión no son derechos propios, sino derechos derivados del ejercicio de la libertad de circulación y de residencia por parte de un ciudadano de la Unión ${ }^{55}$.

Esto significa que los derechos de los nacionales de terceros Estados se restringen siempre a la situación en la que su residencia sea necesaria para garantizar el ejercicio efectivo de estos derechos, por parte de un ciudadano de la Unión, por ejemplo, en el caso de menores (hijos del nacional de un tercer Estado $)^{56}$.

30. En Chávez-Vílchez, el Tribunal lo dejó todavía más claro al indicar que los artículos 20 y 21 TFUE no confieren ningún derecho autónomo a los nacionales de un país tercero. Afirmó también que estos derechos no son derechos propios de esos nacionales, sino derechos derivados de los que tiene el ciudadano de la Unión. Y estableció que su objetivo y su justificación está en que si no se reconocen se puede vulnerar las libertades de circulación y de residencia al ciudadano de la Unión ${ }^{57}$.

\section{b) Condiciones para su ejercicio}

31. La Directiva 2004/38 somete el ejercicio de estos derechos a dos condiciones. Una primera relativa al nacional del tercer Estado que exige tener un vínculo familiar -tiene que ser miembro de la familia- de un ciudadano de la Unión. Y la segunda que afecta al ciudadano de la Unión al requerir que éste haya ejercido la libre circulación o residencia.

32. Respecto de la primera condición, la Directiva 2004/38 mantiene un concepto propio de "miembro de familia" ya que en su artículo 2.2 enumera quienes son "miembros de la familia" a los efec-

\footnotetext{
${ }^{53}$ Ibidem, apdo. 31

${ }^{54}$ STJUE de 10 mayo 2017, C-133/15, Chávez-Vílchez, apdo. 52, EU:C:2017:354, STJUE de 15 noviembre 2011, C-256/11, Dereci, apdo. 56, EU:2011:734; STJUE de 6 diciembre 2012, C 356/11 y C 357/11, O. S., apdo. 41, EU:C:2012:776, y STJUE de 18 diciembre 2014, C 202/13, McCarthy, apdo. 36, EU:C:2014:2450.

${ }_{55}^{55}$ STJUE de 13 septiembre 2016, C-165/14, Redón Marín, apdo. 36, EU:C:2016:675.

${ }^{56}$ Ibidem.

${ }^{57}$ STJUE de 10 mayo 2017, C-133/15, Chávez-Vílchez, apdo.62, EU:C:2017:354.
} 
tos de la aplicación de sus disposiciones. Esta disposición enumera los que son miembros de la familia: el cónyuge (letra a); el miembro de la unión registrada en virtud de la legislación de un Estado miembro, condicionado a que en el Estado miembro de acogida se trate a las uniones registradas igual que a los matrimonios y de conformidad con las condiciones establecidas en la ley del Estado miembro de acogida (letra b); los descendientes directos menores de 21 años o los que estén a cargo del ciudadano de la Unión, y los de su cónyuge o del miembro de la unión registrada (letra c) y finalmente, los ascendientes directos a cargo y los del cónyuge o de la unión registrada (letra d).

Respecto del concepto cónyuge, debe entenderse la persona unida a otra por vínculo de matrimoni $^{58}$. Este concepto de cónyuge de la Directiva es también un concepto propio ya que la letra a del art. 2.2 de la Directiva no remite al derecho de los Estados miembros, como hacen otras letras de la misma norma ${ }^{59}$. El Tribunal de Justicia ha establecido que este concepto propio es, desde el punto de vista del género, neutro, por lo que el ciudadano de la Unión y el del tercer Estado pueden ser del mismo sexo ${ }^{60}$. Este concepto es únicamente aplicable cuando se trata de conceder el derecho de residencia derivado a un nacional de un tercer Estado por aplicación de la Directiva mencionada.

33. Respecto de la segunda condición, que ya ha sido tratada anteriormente, basta recordar aquí que el Tribunal ha afirmado que los ciudadanos de la Unión que nunca han ejercido su derecho a la libre circulación tienen en todo caso el derecho de residencia, de tal manera que puede ser necesario reconocer la residencia al nacional del tercer Estado cuando lo contrario vulnere el efecto útil de la ciudadanía de la Unión, por el hecho de que el ciudadano europeo se vea obligado a abandonar el territorio de la Unión en su conjunto ${ }^{61}$.

34. En principio, el Derecho de residencia se posee por los nacionales de los Estados miembros o de los miembros de sus familias que hayan ejercido el derecho a la libertad de movimientos mediante la presencia en un Estado miembro distinto del Estado cuya nacionalidad ostenta ${ }^{62}$. No obstante, en ciertas circunstancias el derecho a residir de un ciudadano europeo en el Estado cuya nacionalidad ostenta puede afectar y estar protegido por las disposiciones de los arts. 20.2 y 21 TFUE $^{63}$.

35. Como ya se ha indicado antes, la Directiva $2004 / 38$ no es aplicable a los nacionales de terceros Estados que solicitan un derecho de residencia para reunirse con ciudadanos de la Unión miembros de su familia que nunca han ejercido su derecho de libre circulación y siempre han residido en el Estado miembro cuya nacionalidad poseen ${ }^{64}$.

Sin embargo, estos ciudadanos de la Unión pueden invocar las disposiciones del Tratado relativas a la ciudadanía de la Unión siempre que no se trate de una situación puramente interna, esto es, cuando de la residencia del nacional del tercer Estado depende el efectivo disfrute del derecho de residencia de un ciudadano de la Unión ${ }^{65}$.

Antes se ha indicado que los derechos de los nacionales de terceros Estados se restringen a la situación en la que la residencia a favor de un nacional de un tercer Estado sea necesaria para garantizar el ejercicio efectivo por parte de un ciudadano de la Unión, por ejemplo, en el caso de menores (hijos del nacional de un tercer Estado).

${ }^{58}$ STJUE de 25 julio 2008, C-127/08, Metock y otros, apdos. 98 y 99, EU:C:2008:449 y STJUE de 5 junio 2018, C-672/16, Coman, apdo. 34, EU:C:2018:134.

${ }^{59}$ Por lo tanto, los Estados miembros no pueden alegar su derecho interno para considerar que un matrimonio homosexual no es "cónyge" de un ciudadano de la Unión. STJUE de 5 junio 2018, C-672/16, Coman, EU:C:2018:134.

${ }^{60}$ Ibidem, apdo. 35.

${ }^{61}$ STJUE de 8 marzo 2011, C-34/09, Ruiz Zambrano, apdos. 43 y 44 EU:C:2011:124; STJUE de 15 noviembre 2011, C-256/11, Dereci, , apdos. 66 y 67, EU:2011:734; STJUE de 13 septiembre 2016, C-165/14, Redón Marín, apdo. 74, EU:C:2016:675 y STJUE de 10 mayo 2017, C-133/15, Chávez-Vílchez, apdo. 63, EU:C:2017:354.

${ }^{62}$ STJUE de 5 mayo 2011, C-434/09, McCarthy, EU:C:2011:277.

${ }^{63}$ STJUE de 8 marzo 2001, C-34/09, Ruiz Zambrano, EU:C:2011:124.

${ }^{64}$ STJUE de 15 noviembre 2011, C-256/11, Dereci, apdo. 58, EU:2011:734

${ }^{65}$ Ibidem. 
36. En Chávez-Vilchez el Tribunal precisa cuales son las circunstancias relativas a la dependencia entre el menor y el progenitor nacional de un tercer Estado, que deben concurrir, de modo que si se le denegase el derecho de residencia -o un permiso de trabajo- por un Estado miembro, el menor -ciudadano de la UE-, no podría ejercer sus derechos de residencia y circulación.

Esa dependencia puede existir incluso cuando el otro progenitor del menor sea realmente capaz de asumir por sí solo el cuidado diario y efectivo del menor y esté dispuesto a ello ${ }^{66}$. Esta circunstancia, es un elemento pertinente pero no suficiente para poder declarar que no existe entre el progenitor nacional de un país tercero y el menor una relación de dependencia tal que diese lugar a que este último se viese obligado a abandonar el territorio de la Unión en su conjunto en caso de que se produjese esa denegación.

Todas estas circunstancias deben ser tenidas en cuenta por el juez nacional, pero el Tribunal indica cuales son los factores que deben ser analizados para la toma de decisión, siempre garantizando el interés superior del niño; estos son la edad, el desarrollo físico y emocional del menor, la intensidad de su relación afectiva con ambos progenitores y del riesgo de separarlo del progenitor nacional de un tercer Estado ${ }^{67}$.

En todo caso, esa relación de dependencia debe ser probada por el progenitor solicitante de la residencia ya que éste tendrá que aportar los datos que permitan acreditar que una decisión que deniegue el derecho de residencia al progenitor de un país tercero privaría al menor del disfrute efectivo del contenido esencial de los derechos vinculados al estatuto de ciudadano de la Unión, obligándole a abandonar el territorio de la Unión en su conjunto ${ }^{68}$.

37. Aunque la Directiva 2004/38 no sea aplicable al momento de regreso al Estado de origen del ciudadano de la Unión, el Tribunal de Justicia ha declarado que los requisitos de concesión de un derecho de residencia derivado, en virtud del artículo 21.1 TFUE, a un nacional de un tercer país, miembro de la familia de este ciudadano de la Unión, "no deberían ser más estrictos que los establecidos por la Directiva 2004/38 para la concesión de tal derecho de residencia a un nacional de un tercer país, miembro de la familia de un ciudadano de la Unión, que ha ejercido su derecho de libre circulación estableciéndose en un Estado miembro distinto del de su nacionalidad"69.

\section{C) Situaciones reguladas por la Directiva 2004/38}

38. El artículo 3 de la Directiva 2004/38 establece su ámbito de aplicación en el apartado primero, cuando indica que La presente Directiva se aplicará a cualquier ciudadano de la Unión que se traslade a, o resida en, un Estado miembro distinto del Estado del que tenga la nacionalidad, así como a los miembros de su familia, tal como se definen en el punto 2 del artículo 2, que le acompañen o se reúnan con él.

De modo que no establece un régimen aplicable a todos los supuestos que pueden alcanzar los artículos 20 y 21 TFUE sino sólo una parte de ellos, los casos de nacionales y de los miembros de sus familias que se trasladen a, o residan en, un Estado miembro distinto del Estado del que tenga la nacionalidad.

39. El Tribunal de Justicia ha declarado que, dado que la Directiva 2004/38 pretende únicamente regular los requisitos de entrada y residencia de un ciudadano de la Unión en Estados miembros distintos del de su nacionalidad, sus disposiciones no pueden dar soporte a un derecho de residencia derivado en favor de los nacionales de terceros Estados, miembros de la familia de un ciudadano de la Unión, en el Estado miembro del que éste es nacional ${ }^{70}$. Sin embargo, si que influye en este último estableciendo un

${ }^{66}$ STJUE de 10 mayo 2017, C-133/15, Chávez-Vílchez, apdo. 72, EU:C:2017:354.

${ }^{67}$ Ibidem.

${ }^{68}$ STJUE de 10 mayo 2017, C-133/15, Chávez-Vilchez, apdo. 78, EU:C:2017:354.

${ }^{69}$ STJUE de 10 mayo 2017, C-133/15, Chávez-Vílchez, apdo. 54, EU:C:2017:354 y STJUE de 12 marzo 2014, C 456/12, O. $y$ B., apdo. 50, EU:C:2014:135.

${ }^{70}$ STJUE de 10 mayo 2017, C-133/15, Chávez-Vỉlchez, apdo. 53 y STJUE de 12 marzo 2014, C 457/12, S. y G., apdo. 34 , EU:C:2014:136. 
techo de exigencias, ya que cómo se acaba de mencionar en el epígrafe anterior el Tribunal los requisitos para la concesión del derecho de residencia, en el caso del regreso al Estado del que se es nacional no pueden ser más estrictos que los establecidos en la Directiva.

40. El apartado 2 del art. 20 TFUE remite, el régimen del ejercicio de estos derechos a las condiciones previstas en las normas de desarrollo de los mencionados preceptos del Tratado. Esto es, según lo previsto en la Directiva 2004/38. Esta norma refuerza las libertades para hacer más fácil el ejercicio de estas libertades para los sujetos mencionados estableciendo un régimen común del Derecho de salida (art. 4), de entrada (art. 5) y del de residencia diferenciando este derecho en función del período: hasta seis meses (arts. 6-15) y el permanente (arts. 16-21) ${ }^{71}$.

41. Para los objetivos de este trabajo, que se limita al orden público en materia de familia, interesan las condiciones que la Directiva impone para el ejercicio de estas libertades a las personas que no son trabajadores por cuenta ajena o propia en el art. 7.1, letra b. Esta norma exige dos requisitos que deben cumplirse cumulativamente, por un lado, que los beneficiarios dispongan de un seguro de enfermedad que cubra todos los riesgos en el Estado miembro de acogida y, por otro lado, que el ciudadano tenga recursos suficientes para él mismo y para los miembros de su familia con el fin de evitar convertirse en una carga para el sistema de protección social del Estado de acogida ${ }^{72}$.

La suficiencia de los recursos exigibles por parte del Estado de acogida, no puede consistir en una cantidad fija ni superar ciertos límites (art. 8.4 de la Directiva 2004/38).

42. Respecto de la primera, el Derecho de la Unión permite que un Estado miembro pueda exigir, para que un nacional -estudiante o persona que no realice una actividad económica- pueda disfrutar del derecho de residencia en el Estado de acogida que disponga para sí mismo y para los miembros de su familia de un seguro de enfermedad que cubra todos los riesgos en el Estado miembro de acogida (art. 7-1 letra b) Directiva 2004/38) ${ }^{73}$.

Sin embargo, en aplicación del principio de proporcionalidad, el TJUE ha establecido que el Estado miembro de acogida no puede dejar de reconocer este derecho de residencia y de circulación por el mero hecho de que el seguro de enfermedad no cubre los tratamientos de emergencia en dicho Estado ${ }^{74}$.

43. Respecto de la segunda, uno de los aspectos más controvertidos que se ha presentado en relación a la intervención del orden público ha sido la condicionalidad del derecho de residencia por más de tres meses a la disposición de medios para subsistir, con el fin de que la residencia en el Estado de acogida no suponga una carga para el erario público (art. 7.1, letra b Directiva 2004/38) ${ }^{75}$.

Pero también aquí las condiciones y los límites a que sometan los Estados el ejercicio de los derechos fundamentales de los ciudadanos europeos y de sus familiares deben respetar los límites impuestos por el Derecho de la UE y los principios generales de éste, en particular el principio de proporcionalidad, de modo que el origen de los recursos es irrelevante. El TJUE ha establecido que el beneficiario de la libertad europea no debe disponer él mismo de tales recursos, por ejemplo, si es un menor, sino que puede valerse a este respecto de los recursos de un miembro de la familia que lo acompañe ${ }^{76}$.

Las condiciones del art. 7 deben ser cumplidas por quien alegue ese derecho, tanto si se trata de un ciudadano de la Unión (art. 7.1) como si se trata del familiar de éste, nacional de un tercer Estado (art. 7.2).

\footnotetext{
${ }^{71}$ Estas disposiciones regulan las condiciones que deben cumplirse, los trámites administrativos, el procedimiento y la documentación a presentar.

${ }^{72} \mathrm{La}$ letra c regula las normas para los estudiantes.

${ }^{73}$ STJUE de 19 octubre 2004, C-200/02, Zhu and Chen v. Secretary of State of the Home Department, apdo. 27 EU:C:2004:639, en aplicación de la Directiva 90/364 sustituida por la 2004/38.

${ }^{74}$ STJUE de 17 septiembre 2020, C-413/99, Baumbast, EU:C:2001:385.

${ }^{75}$ STJUE de 10 mayo 2017, C-133/15, Chávez-Vilchez, EU:C:2017:354

${ }^{76}$ Ibidem apdo. 29.
} 
44. La Directiva establece finalmente el régimen de los límites a estas libertades por razones de orden público, seguridad y salud públicas, así como las garantías en su aplicación (arts. 27-33). Es en el ámbito de aplicación de los límites nacionales admitidos por el Derecho de la Unión donde se produce el choque entre los principios derechos fundamentales que conformarían el orden público de la Unión y el de los Estados miembros, esta cuestión se tratará en el apartado IV.

\section{4) Situaciones puramente internas.}

45. Los derechos fundamentales pertenecientes al Derecho de la Unión no son aplicables a las situaciones meramente internas. Tradicionalmente, el TJUE ha sostenido que las libertades del mercado interior no son aplicables a las situaciones internas ${ }^{77}$. Esta jurisprudencia impedía que, por ejemplo, un trabajador que no hubiera ejercido la libre circulación de trabajadores del art. 45 TFUE pudiera alegar dicha libertad para obtener la residencia de un familiar nacional de un tercer Estado ${ }^{78}$. Este tratamiento de las situaciones puramente internas se aplicó también en relación a la libre circulación del Tratado de la Comunidad Europea y continuó también tras adoptarse las nuevas libertades de residencia y circulación después en el Tratado de Maastricht ${ }^{79}$.

46. Se han planteado problemas de delimitación entre situaciones puramente internas y las sometidas al Derecho de la Unión en las que afectan a sujetos dobles nacionales (A) y en los supuestos en los que hay una ausencia de traslado (B).

\section{A) La doble nacionalidad}

47. Respecto de la doble nacionalidad, el Tribunal de Justicia ha afirmado que no son puramente internas las situaciones que impliquen a sujetos que ostenten una doble nacionalidad, aunque el niño no hubiera ejercido todavía la libre circulación de personas porque nunca salió de su país de residencia ${ }^{80}$.

Así, la nacionalidad ha servido en García Avelló (nacional español y belga con residencia legal en Bélgica que solicita se inscriban los apellidos en el registro belga conforme a la legislación española) para alegar la libre circulación sin haberla ejercido con anterioridad ${ }^{81}$.

Por el contrario, el Tribunal de Justicia realizó una interpretación más estricta del elemento transnacional y en McCarthy consideró que se trataba de una situación puramente interna en el caso de una doble nacional (irlandesa y británica) que nunca se había desplazado desde el Reino Unido, lugar de su residencia habitual ${ }^{82}$. En dicho supuesto, entendió el Tribunal, no se puede alegar el art. 21 TFUE y la Directiva 2004/38 para eludir la normativa nacional de extranjería y obtener la residencia de un cónyuge nacional de un tercer Estado. Es decir, el mero hecho de la doble nacionalidad no convierte la situación del ciudadano de la Unión en susceptible de afectar a las libertades de residencia y circulación.

El Tribunal de Justicia en el caso McCarthy estableció que el artículo 21 TFUE no es aplicable a un ciudadano de la Unión que nunca ha hecho uso de su derecho de libre circulación, que siempre ha residido en un Estado miembro cuya nacionalidad posee y que tiene además la nacionalidad de otro Estado miembro, siempre y cuando la situación de ese ciudadano no implique la aplicación de medidas de

${ }^{77}$ Para la libre circulación de trabajadores, véanse, STJUE de 28 marzo 1979, C-175/78, R c. Saunders, EU:C:1979:88; STJUE de 27 octubre 1982, Casos 35 y 36/82, Morson and Jhanjan c. Países Bajos, EU:C:1982:368 y STJUE de 5 junio 1997, C-64 y 65/96, Uecker y Jacquet c. Land Nordrhein-Westfallen. EU:C:1997:285.

${ }^{78}$ STJUE de 27 octubre 1982, Casos 35 y 36/82, Morson and Jhanjan c. Países Bajos, EU:C:1982:368.

${ }^{79}$ En relación al derecho a la libertad de circulación de las personas establecido en el artículo 8 A TCE véase, STJUE de 29 mayo 1997, C-299/95, Kremzow c. Austria, EU:C:1997:254 y STJUE de 5 junio 1997, C-64 y 65/96, Uecker y Jacquet c. Land Nordrhein-Westfallen. EU:C:1997:285.

${ }^{80}$ STJUE de 2 octubre 2003, C-148/02, García Avelló, apdos 13 y 27, EU:C:2003:539.

${ }^{81}$ En ambos casos los niños no habían traspasado la frontera en momento de alegar la libertad de circulación y residencia, pero, indudablemente la norma de un Estado miembro (el de origen) disuade de su ejercicio.

${ }^{82}$ STJUE de 5 mayo 2011, C-434/09, McCarthy, EU:C:2011:277. 
un Estado miembro que tengan como efecto privarle del disfrute efectivo de la esencia de los derechos conferidos por el estatuto de ciudadano de la Unión u obstaculizar el ejercicio de su derecho a circular y residir libremente en el territorio de los Estados miembros ${ }^{83}$.

\section{B) Ejercicio de las libertades europeas sin traslado}

48. La ciudadanía europea no está vinculada directa y exclusivamente con la movilidad de los ciudadanos entre Estados miembros, sino que el derecho de residencia es independiente del de circulación, de tal manera que no deben siempre presentarse de manera conjunta ${ }^{84}$.

Por tanto, no se requiere siempre que el sujeto haya traspasado la frontera desde un Estado miembro a otro; la doble nacionalidad, como se ha indicado antes, ha sido suficiente para entender que la medida nacional afecta a la libre circulación de personas en García-Avello (nacional español y belga con residencia legal en Bélgica que solicita se inscriban los apellidos conforme a la legislación española $)^{85}$.

También en el caso Zhu Chen el menor no había abandonado su lugar de nacimiento (Reino Unido), pero se consideró cumplido el requisito del elemento internacional ya que se pretendía su residencia en el Reino Unido -un Estado distinto al de una de sus nacionalidades-.

En el caso Ruiz Zambrano dos niños nacidos y residentes en Bélgica que no habían salido de su país cuya nacionalidad ostentan, alegan las libertades para solicitar la reunificación familiar de sus padres, dos sujetos de nacionales de un tercer Estado. El Tribunal de Justicia consideró que la negativa a otorgar la residencia y el permiso de trabajo del progenitor de los menores ciudadanos de la UE constituía un obstáculo al ejercicio del derecho de residencia previsto en el art. 20 TFUE dado que previsiblemente tendría que abandonar la UE ${ }^{86}$. Pero, como se ha indicado antes, la ausencia del ejercicio previo de la libre circulación no debe asimilarse a una situación meramente interna ya que en el Tribunal indicó que el art. 20 TFUE prohíbe las medidas nacionales que tienen un efecto de impedir a los ciudadanos de la Unión del disfrute efectivo de la esencia de los derechos conferidos por ese estatuto ${ }^{87}$.

Esta situación que se produjo, a juicio del Tribunal, en los casos Ruiz Zambrano y García-Avelló y no en el caso McCarthy ya que la señora McCarthy -que tampoco nunca traspasó la frontera- no se vería obligada a abandonar la UE por el hecho de que su marido (nacional jamaicano) debiera cumplir los requisitos previstos en la ley de extranjería británicos.

La diferencia de estos casos está en el grado de dependencia del ciudadano de la Unión de su familiar, nacional del tercer Estado.

Esta misma línea argumental sigue el Tribunal de Justicia en el caso Dereci. El Tribunal sostiene que Austria, denegando la residencia en su territorio de un nacional turco que entró ilegalmente en Austria y se casó con una nacional austríaca, no vulnera el derecho de residencia del primero, cuando ese nacional pretende residir con un miembro de su familia, que ya reside en Austria y no ha ejercido nunca su derecho de libre circulación, siempre que tal denegación no implique privar a la ciudadana de la Unión del disfrute efectivo del contenido esencial de los derechos conferidos por el estatuto de ciudadano de la Unión ${ }^{88}$.

Considerando el Tribunal en este caso que el criterio relativo a la privación del contenido esencial de los derechos conferidos por el estatuto de ciudadano de la Unión guarda relación con situaciones caracterizadas por la circunstancia de que el ciudadano de la Unión se vea obligado de hecho a abandonar no sólo el territorio del Estado miembro del que es nacional, sino también la Unión en su conjunto ${ }^{89}$.

\footnotetext{
${ }^{83}$ Ibidem.

${ }^{84}$ STJUE de 8 marzo 2001, C-34/09, Ruiz Zambrano, apdo. 26, EU:C:2011:124, véanse también las Conclusiones del Abogado General, Sra. Eleanor Sharpston, presentadas el 30 de septiembre de 2010 1(1), Asunto C-34/09, Gerardo Ruiz Zambrano contra Office national de l'emploi (ONEM), apartado 75. https://curia.europa.eu/juris/liste.jsf?language=es\&num=C-34/09.

${ }^{85}$ En ambos casos los niños no habían traspasado la frontera en momento de alegar la libertad de circulación y residencia, pero, indudablemente la norma de un Estado miembro (el de origen) disuade de su ejercicio.

${ }^{86}$ STJUE 8 marzo 2001, C-34/09, Ruiz Zambrano, apdo. 42-45, EU:C:2011:124.

${ }^{87}$ STJUE de 5 mayo 2011, C-434/09, McCarthy, apdo. 47, EU:C:2011:277

${ }^{88}$ STJUE de 15 noviembre 2011, C-256/11, Dereci, apdo. 74, EU:2011:734.

${ }^{89}$ Ibidem, apdo. 66.
} 


\section{Límites a las libertades europeas que afectan al orden público en Derecho de familia}

\section{Coexistencia de principios fundamentales de los ordenamientos jurídicos europeo y nacional}

49. Ante una situación con elementos internacionales, en los términos requeridos por los arts. 20 y 21 TFUE, además de la aplicación de los derechos fundamentales de cada uno de los Estados miembros deben aplicarse los principios fundamentales del Derecho de la Unión. Por tanto, coexisten los principios fundamentales de ambos ordenamientos, el europeo y el nacional. En este apartado se tratarán las reglas de convivencia de los principios fundamentales del ordenamiento jurídico europeo y del de los Estados miembros.

En los apartados anteriores se ha abordado el ámbito de aplicación de los derechos fundamentales de la Unión y en este se establecerán las relaciones y el procedimiento de solución de los conflictos entre los principios fundamentales de uno y otro ordenamiento jurídico.

50. Se ha indicado ya que el que denominaríamos "orden público europeo" se aplica cuando la situación jurídica interesa a las libertades europeas, pero, la coexistencia de derechos fundamentales se produce por el reconocimiento por el propio Tratado de Funcionamiento y por el Derecho derivado de que las libertades europeas no son ilimitadas y de que los Estados miembros, concurriendo ciertos motivos, pueden adoptar medidas restrictivas de las mismas. En la defensa de las medidas estatales que pueden vulnerar o restringir las libertades europeas se produce la tensión de principios de los dos ordenamientos jurídicos ${ }^{90}$.

51. Así, respecto de las libertades económicas del mercado interior, el art. 36 TFUE prevé cuales pueden ser los motivos para limitar la libre circulación de mercancías, para nombrar las razones de orden público, moralidad y seguridad públicas, protección de la salud y vida de las personas y animales, preservación de los vegetales, protección del patrimonio artístico, histórico o arqueológico nacional o protección de la propiedad industrial y comercial. Por su parte, los arts. 52 y 62 TFUE prevén la posibilidad de aplicación de normas nacionales justificadas por razón de orden público, seguridad y salud públicas que limiten el Derecho de establecimiento del art. 49 TFUE y la libre prestación de servicios del art. 56 TFUE $^{91}$.

Además de estos límites el TJUE ha creado el límite del interés general como se verá más adelante.

52. Los conflictos entre los principios fundamentales de los dos ordenamientos jurídicos se resuelven mediante la aplicación de la llamada rule of reason ${ }^{92}$.

El enfoque que se utiliza respecto de las libertades de circulación y residencia es el mismo realizado por el Tribunal de Justicia en la aplicación del resto de libertades del mercado interior, en particular de la libre circulación de mercancías desde el asunto Cassis de Dijon. El Tribunal estableció el principio de mutuo reconocimiento como regla general a la que pueden plantearse limitaciones o justificaciones "razonables" de los Estados miembros que deberán analizarse caso por caso y tendrán que superar el test de la proporcionalidad".

\footnotetext{
${ }^{90}$ Para un estudio de esta tensión entre los principios nacionales y los establecidos en las convenciones internacionales, desde un punto de vista de Derecho Internacional Privado, véase. R. BARATTA, "Recognition of foreign personal and family status: a rights based perspective", RDIPP, núm. 2, 2016, pp. 413-444.

${ }^{91}$ A L Calvo Caravaca/ J. Carrascosa GonzÁlez, Mercado Único y libre competencia en la Unión Europea, Colex, Madrid, 2003, pp. 157-173.

${ }_{92}$ En el caso Dassonville, el Tribunal acepta que se produzcan restricciones razonables a la libre circulación de mercancías P. Craig \& G. DE BúrCA, EU Law. Text, cases and Materials, Oxford, University Press, 2020, p. 702.

${ }^{93}$ STJ de 20 febrero 1979, Rewe-Zentral $A G$, asunto 120/78, apdo. 8 segundo párrafo, EU:C:1979:42 afirma que deben aceptarse medidas restrictivas siempre que sean necesarias para cumplir las exigencias imperativas relativas a y enumera varios objetivos. Al igual que el párrafo 6 del caso Dassonville, en el que se indica que en tanto no exista un régimen único los Estados pueden adoptar medidas para conseguir un fin "legítimo" siempre que se trate de medidas razonables, STJ de 11 julio 1974 , asunto 8/74, Dassonville, apdo. 6. EU:C:1974:82. Esta teoría para la derogación de las libertades europeas con base en motivos que deben ser considerado legítimos atendiendo a razones imperiosas de interés general.
} 
Es decir, no hay una per se rule mediante la que se establezca con carácter general las medidas estatales compatibles, "justificadas" las califica el Tribunal y las que no son compatibles o no están justificadas y, por tanto, vulneran el Derecho de la Unión.

En las situaciones relativas al Derecho de Familia el principio del reconocimiento puede chocar con los principios que rigen una determinada institución en Derecho nacional, por ejemplo, el principio de igualdad de todos los ciudadanos y los apellidos de una persona; la unión heterosexual en el matrimonio o el modo de establecimiento de los vínculos de filiación. Así, el reconocimiento de situaciones jurídicas relativas a la persona: por ejemplo, el principio de igualdad en el reconocimiento de los apellidos otorgados en un país a una persona se plantea, explícitamente, en el caso Wittgenstein, o el de la condición de cónyuge otorgada en un Estado con ocasión de un matrimonio homosexual, en el caso Coman o la relación de filiación constituida en España en el caso V.M.A.

En este ámbito de aplicación de las libertades de la Unión que afectan al derecho de familia se manifiesta la tensión entre el derecho de familia de los Estados miembro que consagra los valores nacionales y los estándares de protección de los derechos humanos en la Carta ${ }^{94}$.

A continuación, se describe el método de razonamiento que se sigue para aplicar e interpretar las limitaciones a las libertades de circulación y residencia y como conviven los principios fundamentales de los distintos Estado de la Unión.

53. Es necesario recordar, de manera previa dos ideas fundamentales sobre esta convivencia En primer lugar, que el orden público como justificación de una restricción a la libertad de circulación o de residencia debe ser interpretado en sentido estricto ${ }^{95}$. Como el derecho a la ciudadanía de la UE está contenido en el Título V de la Carta de Derechos Fundamentales se deduce que los límites deben ser aplicados de manera restrictiva ${ }^{96}$. Esta interpretación estricta tiene como consecuencia que su invocación solo es posible en caso de que exista una amenaza real y suficientemente grave que afecte a un interés fundamental de la sociedad.

En segundo lugar, los Estados miembros no tienen la facultad de determinar de manera unilateral su alcance, sino que éste y la pertinencia de su alegación están sometidos al control de las instituciones de la UE ${ }^{97}$.

54. Existe jurisprudencia consolidada que establece que una restricción a la libre circulación puede justificarse si se basa en consideraciones objetivas de interés general y es proporcionada al objetivo legítimamente perseguido por el Derecho nacional ${ }^{98}$.

A pesar de que la legislación no incluye el interés general como límite a las libertades europeas, el Tribunal de Justicia ha admitido que los Estados miembros puede restringir las mismas por razones de interés general. La interpretación de este concepto ambiguo de "los motivos de interés general" parece ser el elemento del que partir para determinar la esencia del orden público nacional que puede justificar una restricción a la libre circulación de personas del art. 21 TFUE $^{99}$.

55. Según la jurisprudencia del Tribunal de Justicia, y como se verá a continuación, las medidas nacionales que puedan obstaculizar el ejercicio de las libertades fundamentales garantizadas por el TFUE deben reunir cuatro requisitos para estar justificadas. Estas medidas deben aplicarse de manera no discriminatoria, deben encontrar justificación en razones imperiosas de interés general; deben ser ade-

\footnotetext{
${ }^{94}$ Para una visión general del problema, véase, R. BARATTA, "Recognition of foreign personal and family status: a rights based perspective", RDIPP, núm. 2, 2016, 413-444.

${ }^{95}$ STJUE de 5 junio 2018, C-672/16, Coman, apdo. 44, EU:C:2018:134.

${ }^{96}$ P. CRAIG \& G. DE BÚRCA, EU Law. Text, cases and Materials, Oxford, University Press, 2020, p. 901.

${ }^{97}$ STJUE de 22 diciembre 2010, C-208/09, Sayn-Wittgenstein, apdo. 86, EU:C:2010:806, STJUE de 2 junio 2016, C-438/14, Bogendorff, apdo. 67, EU:C:2016:401.

${ }^{98}$ Sentencia de 14 octubre 2008, C353/06, Grunkin- Paul, apdo. 29, EU:C:2008:559; STJUE de 2 junio 2016, C-438/14, Bogendorff, apdo. 48, EU:C:2016:401 y STJUE de 5 junio 2018, C-672/16, Coman, apdo. 41, EU:C:2018:134.

${ }^{99}$ STJUE de 5 junio 2018, C-672/16, Coman, apdo. 41, EU:C:2018:134 y la jurisprudencia allí citada.
} 
cuadas para garantizar la realización del objetivo que persiguen y no pueden ir más allá de lo necesario para alcanzar dicho objetivo ${ }^{100}$.

Por tanto, a continuación se examinará, en primer lugar, si las medidas nacionales que pueden alegarse por los Estados miembros para limitar las libertades europeas están justificadas por razones imperiosas de interés general ${ }^{101}$. Para ello los objetivos perseguibles con la medida nacional deben ser reconocidos como causas legítimas de justificación por parte del Tribunal de Justicia.

En segundo lugar, las medidas nacionales deben ser apropiadas para alcanzar el objetivo perseguido, es decir se examina si constituye el mecanismo adecuado, por eficaz para conseguir el fin. El Tribunal de Justicia realiza un examen detallado y en el caso concreto de la adecuación de la medida para conseguir el objetivo alegado por el Estado, analizando la efectiva consecución de los objetivos ${ }^{102}$.

En tercer lugar, las medidas nacionales deben ser proporcionadas y no discriminatorias. Es decir, los Estados deben utilizar medios apropiados y proporcionados. De modo que las medidas nacionales no deben ir más allá de lo necesario para conseguir el objetivo perseguido. En este sentido deben examinarse si existen medidas menos limitativas de la libertad europea.

Se trata de condiciones cumulativas, de tal menara que basta con que no la medida nacional no cumpla una de ellas para que no sea una medida legítima desde el punto de vista de la libre circulación.

\section{Test de legitimidad del objetivo perseguible por el Estado miembro}

56. El Tribunal de Justicia exige, en primer lugar, que la medida nacional que limita la libertad de circulación y de residencia supere un test de legitimidad, de tal manera que exige que la medida sea conforme con los derechos fundamentales garantizados por la Carta ${ }^{103}$. Las situaciones jurídicas en las que se ven comprometidas las libertades de residencia y de circulación afectan a derechos garantizados por la Carta, por ello, el Tribunal examina, en primer lugar, si el objetivo nacional pretendido está alineado -es compatible- con los principios fundamentales de la UE plasmados en la Carta ${ }^{104}$.

57. Las disposiciones de la Carta son de aplicación sólo en ese caso de estar implicada una situación en la que se aplique el Derecho de la Unión (art. 51.1 Carta), tal y como ha recordado el Tribunal de Justicia en los casos en los que ha aplicado las disposiciones relativas a las libertades de circulación y de residencia ${ }^{105}$. Por ello, si la situación no está comprendida en el ámbito de aplicación de las mencionadas libertades, la posible vulneración del derecho al respeto de la vida privada y familiar debe examinarse a la luz del art. 8.1 CEDH y no del art. 7 de la Carta ${ }^{106}$. El Tribunal de Justicia considera que deben darse el mismo sentido y el mismo alcance a estas dos normas porque contienen derechos equivalentes.

De ello se deduce que, en todo caso, se vea aplicado el Derecho de la Unión o no, las autoridades nacionales deben respetar el derecho al respeto de la vida privada y familiar como parte del orden público de la UE o de los Estados miembros. Debe de haber, por tanto, un mínimo común en los principios de uno y otro ordenamiento. Esta coincidencia de los dos textos legales debería minimizar los conflictos

\footnotetext{
${ }^{100}$ Véase las sentencias 31 marzo de 1993, Kraus, C-19/92, Rec.p. I-1663, apartado 32; 30 de noviembre 1995, Gebhard, C-55/94, Rec. p. I-4165, apartado 37; STJ 9 marzo 1999 Centros, C212/97, apartado 34 y sentencia 2003 y STJ 30 septiembre 2003, Inspire Art, C-167/01, apartado 133.

${ }^{101}$ STJUE 30 septiembre 2003, C-, Inspire Art, C-167/01, apartado 108.

${ }^{102}$ STJUE 30 septiembre 2003, C-, Inspire Art, C-167/01, apartados 123-128.

${ }^{103}$ STJUE de 22 diciembre 2010, C-208/09, Sayn-Wittgenstein, apdo. 81, EU:C:2010:806; STJUE de 2 junio 2016, C-438/14, Bogendorff, EU:C:2016:40; STJUE de 13 septiembre 2016, C-165/14, Redón Marín, apdo. 66, EU:C:2016:675 y STJUE de 5 junio 2018, C-672/16, Coman, apdo. 47, EU:C:2018:134. Véase, asimismo, las Conclusiones del Abogado General en el asunto Conclusiones AG J. Kokott de 15 abril 2021, C-490/20, V.M.A., apdo. 68, EU:C:2021:296.

${ }^{104}$ STJUE de 2 junio 2016, C-438/14, Bogendorff, apdo. 35, EU:C:2016:401.

${ }^{105}$ STJUE de 15 noviembre 2011, C-256/11, Dereci, apdo. 70, EU:2011:734 y Conclusiones AG J. Kokott de 15 abril 2021, C-490/20, V.M.A., apdo. 118, EU:C:2021:296.

${ }^{106}$ Ibidem, apdo. 72. Sobre la adhesión de la Unión Europea al CEDH véase, A.L. Calvo Caravaca/J. Carrascosa GonZÁLEZ y otros, Tratado de Derecho Internacional Privado, Vol. 1, Valencia, Tirant Lo Blanc, 2020, pp. 233.
} 
entre el orden público europeo y el de los Estados miembros, dado que todos los Estados de la Unión son Estados firmantes del CEDH.

58. El test de la legitimidad europea se advierte claramente en ciertos pronunciamientos del Tribunal:

El respeto al principio de igualdad alegado por Austria como principio general del Derecho consagrado en el art. 20 de la Carta se aprecia en el caso Sayn-Wittgenstein ${ }^{107}$. La oposición de Austria a inscribir el elemento nobiliario del apellido -adquirido legalmente en otro Estado miembro- se justifica en el principio constitucional de igualdad, principio que se considera el Tribunal legítimo y compatible con el Derecho de la Unión por estar también consagrado en el art. 20 de la Carta ${ }^{108}$.

El Tribunal afirma en Coman, la medida nacional -no considerar cónyuge al miembro de un matrimonio homosexual válidamente celebrado en otro Estado de la Unión- sólo puede justificarse si es conforme con los derechos fundamentales garantizados por la Carta ${ }^{109}$. Por ello, el concepto de "cónyuge" del artículo 2.2, letra a la Directiva 2004/38 debe interpretarse teniendo en cuenta el art. 7 de la Carta que garantiza el derecho al respeto de la vida privada y familiar ${ }^{110}$. Como este derecho fundamental comprende en el concepto de "vida privada y familiar" a una pareja homosexual, la medida estatal que, siendo aplicable la Directiva, no reconoce como "cónyuge" a la persona que ha contraído matrimonio homosexual no superaría el test de la legitimidad.

En el caso V.M.A. se plantea ese mismo test respecto de la constitución del vínculo de filiación de la Directiva 2004/38 para el reconocimiento de la maternidad en Bulgaria. Se plantea la legitimidad del objetivo perseguido por las autoridades búlgaras en relación a la inscripción de un certificado de nacimiento de una pareja de mujeres casada como progenitoras de una menor en relación también al art. 7 de la Carta ${ }^{111}$.

El Tribunal indica, asimismo, que el apellido de una persona es un elemento constitutivo de su identidad y de su vida privada y que su protección se consagra tanto por el art. 7 de la Carta como por el art. $8 \mathrm{CEDH}^{112}$.

\section{Del objetivo legítimo a la identidad nacional}

59. El orden público estatal puede variar de un Estado miembro a otro y de una época a otra. En consecuencia, el Tribunal reconoce que las autoridades nacionales competentes tienen un margen de apreciación, que será ejercido en cada caso y dentro de los límites impuestos por el TFUE ${ }^{113}$. En este contexto de las libertades de circulación y residencia, se ha aceptado que los principios fundamentales que conforman el orden público varían de Estado a Estado, por eso los Estados miembros que alegan justificaciones para las restricciones a las libertades de circulación y residencia han alegado, desde el caso Sayn-Wittgenstein el concepto de identidad nacional del art. 4.2 TFUE. El Tribunal ha aceptado que no es indispensable que la medida restrictiva adoptada por las autoridades de un Estado miembro corresponda a una concepción compartida por el conjunto de los Estados miembros en cuanto a las modalidades de protección del derecho fundamental o interés legítimo controvertido ${ }^{114}$.

${ }^{107}$ S., Álvarez GonzÁlez, “Tribunal de Justicia: Ciudadanía - Sentencia del Tribunal de Justicia de la Unión Europea de 22 de diciembre de 2010, asunto C-208/09, Ilonka Sayn-Wittgenstein y Landeshauptmann von Wien”, REDI, $2011 \mathrm{n}^{\circ} 2$ pp.235-239.

${ }^{108}$ STJUE de 22 diciembre 2010, C-208/09, Sayn-Wittgenstein, apdo. 89, EU:C:2010:806. S. Alvarez GonzÁLez, "Tribunal de Justicia: Ciudadanía - Sentencia del Tribunal de Justicia de la Unión Europea de 22 de diciembre de 2010, asunto C-208/09, Ilonka Sayn-Wittgenstein y Landeshauptmann von Wien”, REDI, $2011 \mathrm{n}^{\circ} 2$, pp.235-239.

${ }^{109}$ STJUE de 5 junio 2018, C-672/16, Coman, apdo. 47, EU:C:2018:134, váease, F. PESCE, "La nozione di "matrimonio": Diritto internazionale privato e diritto materiale a confronto", RDIPP, 2017, pp. 777-819, p. 800.

${ }^{110}$ STJUE de 5 junio 2018, C-672/16, Coman, apdo. 48, EU:C:2018:134.

${ }^{111}$ Conclusiones AG J. Kokott de 15 abril 2021, C-490/20, V.M.A., apdo. 68, EU:C:2021:296.

${ }^{112}$ STJUE de 22 diciembre 2010, C-208/09, Sayn-Wittgenstein, apdo. 52, EU:C:2010:806 y STJUE de 2 junio 2016, C-438/14, Bogendorff, apdo. 49, EU:C:2016:40.

${ }^{113}$ Sentencias de 14 de octubre de 2004, Omega, C 36/02, EU:C:2004:614, apartado 31 y jurisprudencia citada, y de 22 de diciembre de 2010, Sayn-Wittgenstein, C 208/09, EU:C:2010:806, apartado 87).

${ }^{114}$ STJUE de 2 junio 2016, C-438/14, Bogendorff, apdo. 73, EU:C:2016:401. 
Esa relatividad del orden público en el espacio se acepta por el Derecho de la UE, que respeta la diversidad existente entre las distintas las modalidades de protección del derecho fundamental o interés legítimo controvertido.

Con el fin de justificar el carácter fundamental de los objetivos estatales en los casos que afectan a cuestiones esenciales de la organización de la sociedad, los Estados miembros han alegado que los principios que justifican la restricción a las libertades de circulación y residencia forman parte de este concepto de identidad nacional ${ }^{115}$.

El Abogado General en V.M.A. considera que ha habido una evolución y que el concepto de identidad nacional no es un mero objetivo legítimo entre otros que se pueden valorar en el examen de las justificaciones estatales a las limitaciones a las libertades de circulación y residencia ${ }^{116}$.

El concepto de identidad nacional tiene como finalidad preservar los enfoques particulares de cada Estado en relación a las estructuras fundamentales políticas y constitucionales, por tanto, la interpretación que se mantenga será esencial para definir la relación entre el orden público europeo y el orden público estatal ya que, como afirma el Abogado General, la salvaguarda del art. 4.2 TUE puede constituir un límite de los efectos del Derecho de la Unión en ámbitos especialmente sensibles para los Estados miembros y va a permitir la ponderación de intereses del mismo rango.

El establecimiento al mismo nivel de los intereses nacionales del art. 4.2 TFUE y de los principios europeos justifica, para el Abogado General que no se realice el examen de la proporcionalidad, a pesar de que, en los casos Sayn-Wittgenstein y Bogendorff el Tribunal si los realizó, como se explicará en el siguiente epígrafe. Ahora bien, la identidad nacional tiene como límite, en opinión del Abogado General, el respeto de los valores consagrados en el art. $2 T U E^{117}$.

60. Los Estados miembros han acudido al concepto de identidad nacional para justificar el carácter fundamental de la institución del matrimonio en el caso $\operatorname{Coman}^{118} \mathrm{o}$, la forma republicana del Estado, la abolición de la nobleza o la prohibición estricta del uso y de la transmisión de los títulos nobiliarios en el caso Sayn-Wittgenstein y en el caso Bogendorff, y ello a pesar de no estar expresamente establecido en la Constitución de un Estado miembro ${ }^{119}$.

61. El principio de reconocimiento exigido como consecuencia de la aplicación de las libertades europeas no siempre produce una agresión a los principios que conforman la identidad nacional. En el caso Coman el Tribunal considera que la libertad de circulación sólo impone la obligación de reconocer los matrimonios homosexuales a los únicos efectos de permitir la residencia en un Estado miembro -en aplicación de la Directiva 2004/38- pero no implica que el Estado deba reconocer en su derecho nacional el matrimonio entre personas del mismo sexo, ni influye negativamente a la institución matrimonial, por lo que el Derecho de la Unión no afecta a la identidad nacional ni amenaza el orden público estatal ${ }^{120}$.

A similar conclusión llega el Abogado General en el caso V.M.A. respecto de la obligación de reconocer el vínculo de filiación establecido en España a los solos efectos de aplicar la Directiva 2004/38, dado que tal cosa no altera la concepción de la filiación o del matrimonio en Bulgaria ${ }^{121}$.

\footnotetext{
${ }^{115}$ STJUE de 22 diciembre 2010, C-208/09, Sayn-Wittgenstein, apdo. 74, EU:C:2010:806.

${ }^{116}$ Apdo. 82 Conclusiones AG J. Kokott de 15 abril 2021, C-490/20, V.M.A., apdo. 82, EU:C:2021:296.

${ }^{117}$ Ibidem, apdos. 73 y 101-134.

${ }^{118}$ STJUE de 5 junio 2018, C-672/16, Coman, apdo. 42, EU:C:2018:134.

${ }^{119}$ STJUE de 22 diciembre 2010, C 208/09, Sayn-Wittgenstein, apdo. 92, EU:C:2010:806 y STJUE de 2 junio 2016, C-438/14, Bogendorff, apdo. 64, EU:C:2016:401. Sobre la referencia a la constitución de un Estado como fuente de los principios que conforman el orden público internacional, véase, F. SALERno, "La constituzionalizzazione dell'ordine pubblico internazionale", RDIPP, núm. 2, 2018, pp.259-291.

${ }^{120}$ STJUE de 5 junio 2018, C-672/16, Coman, apdos. 45 y 46, EU:C:2018:134.

${ }^{121}$ Conclusiones AG J. Kokott de 15 abril 2021, C-490/20, V.M.A., apdo. 114, EU:C:2021:296
} 


\section{Necesidad y adecuación}

62. Superado el examen de la legitimidad, las medidas nacionales que restringen las libertades de circulación y residencia deben ser necesarias y apropiadas para conseguir la finalidad pretendida por el Estado miembro ${ }^{122}$.

También el análisis de la necesidad y la adecuación debe hacerse en el caso concreto, ya que, el hecho de que se acepte que los Estados discrepen en las modalidades de protección de los derechos fundamentales considerados legítimos, no exime de su superación ${ }^{123}$.

Debe existir por tanto una relación de causa efecto entre la medida nacional restrictiva de las libertades europeas y la consecución del objetivo pretendido ${ }^{124}$.

\section{Proporcionalidad y objetividad de la medida estatal}

63. Superado el examen de la legitimidad, la necesidad y la adecuación, en el análisis de la compatibilidad de la medida estatal con las libertades de circulación y residencia se incluye una valoración de la proporcionalidad y de la objetividad de la medida. Existe jurisprudencia consolidada relativa a la aplicación de estos requisitos a las otras libertades que conforman el mercado interior ${ }^{125}$.

64. El análisis de la proporcionalidad implica la valoración de la existencia de otra manera menos restrictiva de la libertad europea para conseguir el fin pretendido; en relación a las libertades de circulación y de residencia es especialmente interesante esta valoración en los casos Boggendorff y Sayn-Wittengstein ${ }^{126}$.

En el caso Sayn-Wittengstein lleva al Tribunal a valorar que la garantía del principio de igualdad puede justificar la prohibición de la adquisición, la posesión o el uso por sus ciudadanos de títulos nobiliarios o de elementos nobiliarios que pudieran hacer creer que la persona que los utiliza ostenta tal honor. Por lo tanto, un Estado que no reconoce un apellido otorgado por las autoridades de otro Estado miembro no van más allá de lo necesario para la consecución del objetivo pretendido por lo que parece hacer referencia a la mínima restricción ${ }^{127}$.

Por su parte, en el caso Boggendorff el Tribunal no hace, por sí mismo, la valoración de la proporcionalidad, sino que la remite al juez nacional por considerar que está mejor situado para efectuar un análisis ponderado de los elementos jurídicos y de hecho presentes en el caso ${ }^{128}$. No obstante, el Tribunal de Justicia, indica cuales son los criterios que se deben tener en cuenta por el juez nacional en el momento de realizar el control de proporcionalidad ${ }^{129}$.

Por tanto, este test de la proporcionalidad puede llevarse a cabo tanto por el Tribunal de Justicia como por los tribunales nacionales, ante quienes se plantea el conflicto entre los principios fundamentales nacionales y los europeos.

${ }^{122}$ STJUE de 14 octubre 2004, C36/02, Omega, apdo. 36, EU:C:2004:614; STJUE de 10 julio 2008, C33/07, Jipa, apdo. 29, EU:C:2008:396 y STJUE de STJUE de 2 junio 2016, C-438/14, Bogendorff, apdo. 72-77, EU:C:2016:401.

${ }^{123}$ STJUE de 14 octubre 2004, C36/02, Omega, apdo. 337 y 38, EU:C:2004:614; STJUE de 22 diciembre 2010, C 208/09, Sayn-Wittgenstein, apdo. 91, EU:C:2010:806 y STJUE de STJUE de 2 junio 2016, C-438/14, Bogendorff, apdo. 73 , EU:C:2016:401

${ }^{124}$ La aplicación de la ley de la nacionalidad en cada Estado miembro por mandato de la norma de conflicto del Estado de origen pretendía conseguir una determinación estable de los apellidos, sin embargo, en las circunstancias del caso, cada vez que el ciudadano de la UE traspasaba la frontera cambiaba su apellido, así que la medida estatal provocaba el resultado contrario al pretendido. STJUE de 14 octubre 2008, C-353/06, Grunkin-Paul, apdo. 32, EU:C:2008:559.

${ }^{125}$ STJUE de 30 septiembre 2003, C-167/01, Inspire Art, apdo. 140, EU:C:2003:512.

${ }^{126}$ STJUE de 22 diciembre 2010, C 208/09, Sayn-Wittgenstein, apdo. 93, EU:C:2010:806. En el caso Coman no llega a realizarse el análisis porque el Tribunal no considera superado el test de la legitimidad. STJUE de 5 junio 2018, C-672/16, Coman, apdo. 46, EU:C:2018:134 y en el caso V.M.A. el Abogado General entiende que no es necesario hacerlo al tratarse de una medida justificada por el interés nacional y no un objetivo legítimo.

${ }^{127}$ STJUE de 22 diciembre 2010, C 208/09, Sayn-Wittgenstein, apdo. 93, EU:C:2010:806.

${ }^{128}$ STJUE de STJUE de 2 junio 2016, C-438/14, Bogendorff, apdo. 78, EU:C:2016:401.

${ }^{129}$ Ibidem, apdos. 80-84. 
65. Finalmente, las justificaciones deben basarse en consideraciones objetivas, por lo que si la medida resultara discriminatoria no sería compatible con el Derecho de la Unión aunque cumpliera el resto de condiciones.

La Directiva 2004/38 se refiere en su considerando 31 a la prohibición de discriminación de la Carta y a la obligación de los Estados miembros de aplicar sus disposiciones sin discriminar entre los beneficiarios de la presente Directiva por razones como el sexo, raza, color, origen étnico o social, características genéticas, lengua, religión o convicciones, opiniones políticas o de otro tipo, pertenencia a una minoría nacional, patrimonio, nacimiento, discapacidad, edad u orientación sexual.

66. El desarrollo del derecho a la Libre circulación y residencia de los artículos 20 y 21 TFUE se ha producido mediante la Directiva 2004/38/CE y a ella hay que acudir para encontrar los límites. A diferencia de lo que ocurre con las libertades de los factores productivos que conforman el mercado interior, la libertad de residencia y de circulación no se ve limitada por las disposiciones del Tratado de Funcionamiento, sino que éstas remiten a las normas adoptadas para la aplicación del art. 21 a las normas de desarrollo, principalmente, la Directiva 2004/38/CE.

El considerando 22 de la Directiva recuerda que el Tratado prevé algunas restricciones al ejercicio del derecho de libre circulación y residencia por razones de orden público, seguridad pública o salud pública ${ }^{130}$. El capítulo IV de la Directiva recoge las limitaciones del Derecho de entrada y de residencia por razones de orden público, seguridad pública o salud pública (artículos 27-33).

\section{El orden público como límite a las libertades del mercado interior en la Directiva 2004/38}

67. La Directiva 2004/38 no sólo establece las condiciones de ejercicio de los derechos de residencia y de circulación de los ciudadanos de la Unión y de sus familiares sino que también establece cuáles son los límites a dichos derechos por razón de orden público, seguridad pública o salud pública $(\text { art. 1, letra c) })^{131}$.

68. Este Orden Público de cada Estado, también se refiere a las situaciones comprendidas dentro del ámbito de aplicación ratione materiae del Derecho de la Unión, es decir debe tratarse de situaciones en las que se vea implicado el ejercicio de las libertades fundamentales garantizadas por el TFUE y a las que se aplique la Directiva tal y como se ha indicado en el apartado II.3.C. Por lo que aquí interesa se tratarán los aspectos relativos al ejercicio de libertad de circulación y de residencia en el territorio de los Estados miembros, pero también ha sido de aplicación como límite a otras libertades del Mercado Interior, la libre prestación de servicios, la libre circulación de trabajadores y el derecho de establecimiento (arts. 36, 45 y 52 TFUE respectivamente) ${ }^{132}$.

La noción de orden público manejado en el apartado III no debe asimilarse totalmente al término utilizado también por el Tratado y la Directiva como excepción a las libertades europeas.

69. Esta Directiva utiliza también el concepto de orden público junto al de seguridad pública, como límite en los arts. 27.1 y 27.2. Dichos preceptos disponen el régimen que los Estados miembros deben respetar para limitar la libertad de circulación y residencia de los ciudadanos de la Unión por razones de orden público, seguridad pública o salud pública.

${ }^{130}$ Para precisar las condiciones y garantías procesales con arreglo a las cuales puede adoptarse la decisión de denegación de entrada o de expulsión de los ciudadanos de la Unión y de los miembros de su familia, la presente Directiva sustituye a la Directiva 64/221/CEE del Consejo, de 25 de febrero de 1964, sobre coordinación de las medidas especiales para los extranjeros en materia de circulación y de residencia, justificadas por razones de orden público, seguridad pública o salud pública. DO 56 de 4.4.1964, p. 850; Directiva cuya última modificación la constituye la Directiva 75/35/CEE (DO L 14 de 20.1.1975, p. 14).

${ }^{131} \mathrm{El}$ art. 15 regula las garantías del procedimiento que se sigan en los Estados miembros y que tengan como objeto una limitación de estos derechos.

${ }^{132}$ STJUE de 2 junio 2016, C-438/14, Bogendorff, apdo. 31, EU:C:2016:401. En algunos casos el tribunal ha entendido que alegar este orden público para justificar restricciones a la libre prestación de servicios carece de fundamento, véase STJUE de 7 febrero 2002, C-279/00, Comisión c. Italia, apdo. 13, EU:C:2002:89. 
70. Los términos de orden público y de seguridad pública a los que se refiere la Directiva se citan normalmente juntas en las sentencias del Tribunal de Justicia por lo que se deduce que se trata de un concepto distinto al orden público analizado en los apartados anteriores ${ }^{133}$.

Puede considerarse que este orden público se acerca al de seguridad pública cuando se refiere, por ejemplo, a infracciones penales que constituyen un menoscabo especialmente grave de un interés fundamental de la sociedad, cuyo riesgo de reiteración representa una amenaza directa para la tranquilidad y la seguridad fisica de la población, y que, por consiguiente, cabe incluir en el concepto de «motivos imperiosos de seguridad pública» que pueden justificar una medida de expulsión ${ }^{134}$.

71. Esta excepción a las libertades de circulación y residencia de los ciudadanos de la Unión o de sus familiares comparte características con las analizadas anteriormente. Así, este principio, que ha sido llamado reserva y excepción, ha de ser también objeto de interpretación estricta, y su alcance no puede ser determinado unilateralmente por los Estados miembros ${ }^{135}$.

Igualmente, las medidas adoptadas por razones de orden público deben ajustarse al principio de proporcionalidad y basarse exclusivamente en la conducta personal del sujeto ${ }^{136}$.

En aplicación de estas libertades, el Tribunal había exigido tradicionalmente que el recurso a este concepto exige que exista, aparte de la perturbación del orden social que constituye toda infracción de las leyes, una amenaza real y suficientemente grave que afecte a un interés fundamental de la sociedad ${ }^{137}$.

En la aplicación del orden público, en este sentido, el Tribunal de Justicia analiza si un determinado objetivo constituye un menoscabo especialmente grave de un interés fundamental de la sociedad, cuyo riesgo de reiteración puede entrar en el concepto de "motivos imperiosos de seguridad pública", y "representa una amenaza directa para la tranquilidad y la seguridad física de la población". En ese caso, el Tribunal acepta que puede suponer un límite a una libertad europea por ser un motivo imperioso de seguridad pública.

72. En todo caso, ya se ha mencionado que la Directiva 2004/38 establece el respeto de los derechos y libertades fundamentales y observa los principios reconocidos por la Carta de los Derechos Fundamentales de la Unión Europea. De modo que impone a los Estados miembros la aplicación de este orden público sin discriminar por razones como el sexo, raza, color, origen étnico o social, características genéticas, lengua, religión o convicciones, opiniones políticas o de otro tipo, pertenencia a una minoría nacional, patrimonio, nacimiento, discapacidad, edad u orientación sexual (considerando 31).

${ }^{133}$ STJUE de 13 julio 2017, C-193/16, E y Subdelegación del Gobierno de Álava, apdo.22, EU:C:2017:542

${ }_{134} \mathrm{Ibidem}$, apdo. 20. El ciudadano de la Unión fue expulsado por las autoridades españolas en aplicación del art. 15 del RD 240/2007, por haber sido condenado por sentencia firme a doce años de prisión por haber cometido reiteradamente delitos de abusos sexuales sobre menores.

${ }^{135}$ STJUE de 13 septiembre 2016, C-165/14, Redón Marín, apdo. 65, EU:C:2016:675 y STJUE de 13 julio 2017, C-193/16, E y Subdelegación del Gobierno de Álava, apdo.18, EU:C:2017:542.

${ }^{136}$ STJUE de 13 julio 2017, C-193/16, E y Subdelegación del Gobierno de Álava, apdo. 19, EU:C:2017:542.

${ }^{137}$ También cuando resolvía sobre el orden público como límite a la libre circulación de trabajadores, véase, STJUE de 7 de mayo de 1998, C-350/96, Clean Car Autoservice, apdo. 40, EU:C:1998:205 y STJUE de 9 marzo 2000, C-355/98, Comisión/ Bélgica, apdo.28, EU:C:2000:113. 